Revista Española de Derecho Europeo 78-79 | Abril - Septiembre 2021

pp. 13-52

Madrid, 2021

DOI:10.37417/REDE/num78-79 2021 678

(C) Marcial Pons Ediciones Jurídicas y Sociales

(C) Juan Ignacio Ugartemendia Eceizabarrena ISSN: 2695-7191

Recibido: 20/09/2021 | Aceptado: 08/10/2021

\title{
TURBULENCIAS SOBRE LA PRIMACÍA DEL DERECHO DE LA UE: ÚLTIMOS DESAFÍOS, RESPUESTAS Y APORTACIONES
}

\author{
TURBULENCE OVER THE PRIMACY OF EU LAW: LATEST \\ CHALLENGES, ANSWERS AND CONTRIBUTIONS
}

\author{
Juan Ignacio Ugartemendia Eceizabarrena*
}

RESUMEN: Recientemente se han producido una serie de resoluciones de diversos tribunales constitucionales que vienen a desafiar abiertamente el principio de primacía del Derecho de la Unión, haciendo valer para ello diversos límites derivados de la Constitución nacional. Una vez apuntadas muy sucintamente estas decisiones conflictivas, así como los mecanismos existentes para garantizar la primacía del Derecho de la Unión y los límites que se suelen oponer a la misma, el trabajo se centra en indicar las posibles vías para resolver la contraposición entre norma constitucional y Derecho de la Unión, y en recoger algunas propuestas que pueden contribuir a encauzar este tipo de turbulencias (jurisdiccionales) respecto al principio de primacía. Propuestas tanto en lo concerniente a la posición de la jurisdicción constitucional nacional ante tales conflictos, como a la dinámica decisoria desarrollada por parte del TJUE en los mismos. Buscando puentes sobre aguas turbulentas.

* Profesor Titular (Acreditado como Catedrático) de Derecho Constitucional y de la Unión Europea de la UPV/EHU. Correo-e: j.ugartemendia@ehu.eus. ORCID ID: 0000-0003-3960-4971.

El presente trabajo se ha realizado en el marco del Grupo de Investigación «GIC Derechos Fundamentales y Unión Europea», financiado por el Gobierno Vasco [IT1190-19], así como del PI «Constitucionalismo social y económico: nuevos retos para el Estado de Derecho en Europa» financiado por el MEC [DER2017-84195-P]. 
PALABRAS CLAVE: Derecho de la Unión Europea vs constitución nacional; primacía; interpretación conforme; reforma constitucional; cooperación judicial.

ABSTRACT: Recently, there have been a series of decisions by various constitutional courts that openly challenge the principle of the primacy of EU law, asserting limits derived from the national Constitution. Having very briefly outlined these conflicting decisions, as well as the existing mechanisms for guaranteeing the primacy of Union law and the limits which tend to oppose it, the paper focuses on indicating the possible ways of resolving the clash between constitutional rule and Union law, and on pointing out some proposals which may contribute to channeling this type of (jurisdictional) turbulence with respect to the principle of primacy. These proposals concern both the position of the national constitutional jurisdiction in the face of such conflicts, and the decision-making dynamic developed by the CJEU in such conflicts. Looking for bridges over troubled waters.

KEYWORDS: European Union Law vs national constitution; primacy; consistent interpretation; constitutional reform; judicial cooperation.

SUMARIO: INTRODUCCIÓN.-1. TURBULENCIAS JURISDICCIONALES ACERCA DE LA PRIMACÍA DEL DERECHO DE LA UNIÓN.-2. EL CONTROL Y LOS LÍMITES DE LA PRIMACÍA: 2.1. El control del respeto de la primacía del Derecho de la Unión. 2.2. Los límites del principio de primacía.-3. LAS SALIDAS A LA VULNERACIÓN DEL PRINCIPIO DE PRIMACÍA.-4. NUEVAS APORTACIONES SOBRE LOS MECANISMOS DE SALIDA A LA VULNERACIÓN DEL PRINCIPIO DE PRIMACÍA: 4.1. En relación con la actuación de la jurisdicción constitucional nacional (o de "cómo barrer la propia casa"). 4.2. En relación con la jurisdicción del TJUE (o sobre "cómo escuchar al otro")._CONCLUSIÓN._FUENTES CITADAS.

\section{INTRODUCCIÓN}

El principio de primacía del Derecho de la Unión sobre el Derecho interno ha sido objeto de inusitadas embestidas desde la primavera del pasado año 2020. Se trata, de forma más concreta, de ataques dirigidos contra la primacía del Derecho de la Unión sobre la Constitución nacional que se realizan agitando límites constitucionales nacionales. Límites al Derecho de la Unión (incluidas las decisiones de su supremo intérprete, el Tribunal de Justicia) que son identificados y enarbolados por algunos Tribunales Constitucionales. No se trata de meras infracciones o incumplimientos del Derecho de la Unión, sino de decisiones contra el Derecho de la Unión que tratan de ser justificadas en atención a principios o reglas de la propia Constitución. Una operación que conduce a una insostenible "Europa a la Carta" ${ }^{1}$, a vulnerar el

\footnotetext{
1 Alonso García (2021c, 25 jul.).
} 
principio de igualdad de los Estados ante los Tratados ${ }^{2} \mathrm{y}$, a la postre, a resquebrajar la eficacia y unidad del Derecho de la Unión ${ }^{3}$.

Otro aspecto, a resaltar ahora, consiste en que dichas arremetidas contra la primacía del Derecho de la Unión se han configurado, en gran parte, como desafíos al propio Tribunal encargado de garantizar el respeto de ese Derecho y esa primacía en la interpretación y aplicación de los Tratados, el Tribunal de Justicia de la Unión. Como consecuencia de ello se ha generado una cierta sensación de conflicto o turbulencia entre los Tribunales involucrados y, a la postre, en las alturas del entramado jurisdiccional, europeo y nacional, de la Unión. Por lo demás, es reseñable que, en buena parte de los asuntos involucrados, la materia objeto de conflicto ha sido, además, una cuestión directamente ligada con el núcleo del poder jurisdiccional estatal: el respeto de la independencia judicial por parte del Estado miembro en cuestión a la luz de los estándares del Derecho de la Unión [arts. 2 y 19.1 (2) del TUE y 47 de la Carta de Derechos Fundamentales de la Unión Europea], estándares definidos por el TJ. Turbulencias jurisdiccionales claramente nocivas para la integración supranacional europea, ante las que debe primar el espíritu europeo de la Unión (Hostem repellas longius [...] vitemus omne noxium).

Las páginas que siguen tratan sobre los mencionados desafíos al principio de primacía y sobre las posibles respuestas y salidas frente a los mismos. La estructura que seguirá el trabajo es la siguiente: inicialmente, se señalarán de forma muy breve los asuntos conflictivos a los que venimos aludiendo (punto 1); posteriormente, se realizará una resumida visión contextualizadora del principio de primacía, centrada tanto en las formas de control jurisdiccional existentes para garantizar su respeto como también en los límites que presenta el principio (punto 2); a continuación se reflejará el conjunto de las posibles vías existentes para resolver la contraposición entre norma constitucional y Derecho de la Unión (punto 3); finalmente, se apuntarán una serie de propuestas que pueden contribuir a encauzar este tipo de turbulencias jurisdiccionales respecto al principio de primacía, propuestas tanto en lo concerniente a la posición de la jurisdicción constitucional nacional ante tales conflictos como respecto al ejercicio de la primacía por parte del TJUE (punto 4).

2 Para un análisis de la conexión entre ambos principios de primacía e igualdad véanse: Lenaerts (2020 8 oct., 2020) y Rossi (2017).

3 Como ha recordado recientemente el TJUE, en virtud del principio de primacía del Derecho de la Unión, no puede admitirse que normas de Derecho nacional, aun si son de rango constitucional, menoscaben la unidad y la eficacia del Derecho de la Unión (SSTJUE: W.Ż., 2021, par. 157; Latvijas Republikas Saeima, 2021, par. 135; Asociaţia 'Forumul Judecătorilor Din România' v Inspecția Judiciară, 2021; A.B. y otros, 2021, par. 245; con anterioridad, por ejemplo, SSTJUE: Pelham y otros, 2019, par.78; Minister for Justice and Equality, 2018, par. 49; Križan y otros, 2013, par. 70; o Melloni, 2013, par. 59). 


\section{TURBULENCIAS JURISDICCIONALES ACERCA DE LA PRIMACÍA DEL DERECHO DE LA UNIÓN}

(a) Hay que comenzar con el Bundesverfassungsgericht. El punto de partida de las turbulencias lo marca de forma clara la Sentencia Weiss del Tribunal Constitucional alemán, de 5 de mayo de 2020 4, según la cual la sentencia previa del Tribunal de Justicia en el asunto Weiss y otros 5 (y varias decisiones del Banco Central Europeo sobre el PSPP o programa de compras de valores públicos en mercados secundarios de 2015, cuya corrección fue avalada por esta última resolución) había sido adoptada ultra vires y no es jurídicamente vinculante en Alemania. Como es conocido, el TC federal alemán venía reiterando desde hacía tiempo que el principio de primacía del Derecho de la Unión tenía límites ligados al respeto de la identidad constitucional alemana y a la no actuación europea ultra vires, y que dicho Tribunal se reservaba la competencia para controlar ese respeto. Pues bien, aunque esta no fue la primera ocasión en que realizaba dicho control, sí que ha sido la primera en que, una vez realizado el mismo, el Tribunal alemán ha considerado que la decisión del TJ vulneraba esos límites con la consecuencia de que, por tanto, esta no era vinculante y aplicable en Alemania.

La Sentencia generará muchas y diversas reacciones ${ }^{6}$. Por lo que ahora interesa, debe señalarse, por un lado, la contenida respuesta de la Unión Europea frente a la misma. Por otro lado, la aparición, como veremos en este mismo apartado, de una serie de desafíos jurisdiccionales provenientes de ciertos Estados que, aunque no siempre es posible relacionar con aquella resolución, sí permiten hablar de un cierto efecto mimético de la misma en las decisiones de algunos Tribunales estatales. Por lo que a la réplica de la Unión se refiere, conviene constatar que el TJ no entró a definir su posición respecto a la sentencia del TC alemán, aunque sí emitió un inédito comunicado de prensa referido a la misma ${ }^{7}$, en el cual se limitaba a recordar el carácter vinculante de las sentencias que dicta con carácter prejudicial para el juez nacional, así como su doctrina $\left(\right.$ Foto-Frost $\left.^{8}\right)$ según la cual él es el único Tribunal competente para declarar que un acto de una institución de la Unión es contrario al Derecho de la Unión. Lo que sí realizará el TJ en el recorrido jurisprudencial de los posteriores meses es un interesante aporte -ni fortuito ni inopinado- de breves pero significativas consideraciones acerca de la primacía del Derecho de la Unión sobre las normas constitucionales y sobre la jurisdicción constitucional de los Estados miembros, consideraciones que iremos apuntando en este apartado. Resulta asimismo digna de mención la

4 Sentencia BVerfG - Sala 2. ${ }^{\text {a }}$ (2020).

5 Sentencia TJUE (2018).

6 Véanse al respecto, entre otros: Galetta y Ziller (2020), Martín Rodríguez (2020), López Castillo (2021).

7 TJUE (2020, 8 may.).

8 STJUE (1987, párs.15 y 17). 
postura marcada por el Abogado General E. Tanchev en las Conclusiones presentadas al caso A.B. y otros (sobre recursos en materia de nombramientos de Jueces del Tribunal Supremo de Polonia) en las que, al abordar la cuestión de la primacía del Derecho de la Unión, le dedica cuatro apartados de no poca enjundia a la Sentencia alemana ${ }^{9}$, sin dejar de conectarla, por cierto, con otra resolución de la Sala Disciplinaria del Sąd Najwyższy (Tribunal Supremo, Polonia) que, con posterioridad a aquella resolución del TC alemán, declaraba que una sentencia del Tribunal de Justicia no era vinculante en el ordenamiento jurídico polaco ${ }^{10}$. Más allá del Tribunal de Justicia, es importante dejar constancia también del anuncio de la Comisión Europea, realizado el pasado 9 de junio de 2021, de que incoará un procedimiento de infracción contra Alemania por incumplimiento de los principios fundamentales de la legislación de la UE.

El arriba mencionado caso A.B. y otros será, por cierto, uno de esos asuntos post-Weiss en los que el TJ aprovechará para insistir en los mensajes sobre el principio de primacía del Derecho de la Unión, en este caso subrayando

9 Conclusiones AG (2020, párs. 80-84). En la médula de las consideraciones del Abogado General está la idea de que "de conformidad con los Tratados, que son el «contrato» del Estado miembro, el Tribunal de Justicia será competente para conocer en última instancia de los recursos contemplados en el Derecho de la Unión. Así se desprende claramente del art. 19 TUE y del art. 267 TFUE. Además, de conformidad con lo expresamente establecido en el art. 344 TFUE: «Los Estados miembros se comprometen a no someter las controversias relativas a la interpretación o aplicación de los Tratados a un procedimiento de solución distinto de los previstos en los mismos». Por tanto, en virtud del principio pacta sunt servanda, sencillamente no es función o competencia del BVerfG pronunciarse de la forma en que lo hizo en el asunto Weiss. Con arreglo a los Tratados, ningún órgano jurisdiccional nacional puede revocar una sentencia del Tribunal de Justicia, puesto que entonces el Derecho de la Unión no se aplicaría en condiciones de igualad ni de manera efectiva en los 27 Estados miembros y se pondría en duda toda la base jurídica de la Unión" (par. 84).

10 Se trata del Auto de la Sala Disciplinaria del Tribunal Supremo de Polonia (2020, 23 sep.), en el que se señala que la sentencia del Tribunal de Justicia de la UE en el asunto A. K. y otros (2019, relativo a la independencia de esa Sala Disciplinaria del Tribunal Supremo) «no se puede considerar vinculante en el ordenamiento jurídico polaco, habida cuenta de que en todos los procedimientos pendientes ante la Sala de lo Laboral y de la Seguridad Social del Tribunal Supremo, en los que se plantearon cuestiones prejudiciales al Tribunal de Justicia ([...] una petición de decisión prejudicial registrada en el Tribunal de Justicia [en los asuntos] C585/18, [...] C624/18, [...] [y] C625/18), las actividades se llevaron a cabo a través de formaciones jurisdiccionales que contravenían las disposiciones de la ley» (Ley de 26 de abril de 2019, por la que se modifica la Ley del Consejo Nacional del Poder Judicial y la Ley Reguladora de la Jurisdicción Contencioso-Administrativa). Una afirmación que se realizó, además, a pesar de que el TJ había declarado cautelarmente (mediante Auto de medidas provisionales, de 8 de abril de 2020, Comisión/Polonia) que debían suspenderse las actividades de dicha Sala Disciplinaria hasta que se dictara Sentencia poniendo fin al procedimiento en el asunto (C791/19), una Sentencia a la que aludiremos más adelante. Sobre el Auto que venimos comentando: véase las mencionadas Conclusiones de E. Tanchev, en A.B. y otros, párs. 74 y ss. 
que "los efectos que se asocian" a dicho principio "se imponen a todos los órganos de un Estado miembro", y que, "según reiterada jurisprudencia, resulta inadmisible que normas del Derecho nacional puedan menoscabar la unidad y la eficacia del Derecho de la Unión, aunque se trate de normas de rango constitucional" 11 .

(b) Por otro lado tenemos que destacar la duda generada a propósito de una decisión del Conseil d'Etat francés. Cerca de un año después de la Sentencia Weiss del TC de Karlsruhe, el 21 de abril de 2021, surge otra Sentencia, en este caso del Consejo de Estado francés, que ha dado también pie al debate sobre la primacía ${ }^{12}$. Se trata de una resolución dictada tras la decisión prejudicial del TJ La Quadrature du Net y otros, de 6 de octubre de 2020, en la que el Tribunal de Luxemburgo entiende que el Derecho de la Unión (Directiva 2002/58 sobre privacidad y medios electrónicos y la Carta de DFUE) se opone a una legislación nacional, como la francesa, que exija a un proveedor de servicios de comunicaciones electrónicas que lleve a cabo la transmisión o retención general e indiscriminada de datos de tráfico y datos de ubicación con el fin de combatir la delincuencia en general o de salvaguardar la seguridad nacional ${ }^{13}$. Aunque la Sentencia ha sido entendida como una muestra clara de que el Consejo de Estado rechaza la posición de considerar, como hizo la decisión Weiss del Tribunal alemán, que los tribunales constitucionales (o supremos) de los Estados miembros tienen derecho a revisar una actuación ultra vires de las instituciones europeas (incluido el TJUE) ${ }^{14}$, hay asimismo quienes, de forma antagónica, interpretan que la decisión de la corte suprema administrativa francesa plantea una confrontación abierta, percibiendo la resolución como una auténtica "bomba de racimo contra el orden jurídico y político de la UE”. La resolución podrá, en apariencia, ser menos conflictiva que la del BVerfG alemán, al negarse a considerar ultra vires la decisión previa del TJUE; sin embargo, estaría optando por la vía de la confrontación frente al Tribunal al oponerse abiertamente a la aplicación de la legislación europea del caso "mientras" — Solange securitario — el Derecho de la UE no garantice la seguridad nacional, una cuestión de identidad constitucional para Francia; o, cuando menos, estaría permitiendo al Gobierno francés continuar recopilando datos de conexión personal, a pesar de que el TJUE hubiera ya aclarado específicamente la naturaleza ilegal de estas medidas ${ }^{15}$.

(c) Otro caso de notoria turbulencia es el que tiene lugar con el Curtea Constituăională (Tribunal Constitucional) de Rumanía a raíz de una reforma

11 STJUE A.B. y otros (2021, par. 148). Véase, también, la jurisprudencia previa que citábamos al respecto al comienzo de estas páginas.

12 La Sentencia, por cierto, era dictada el mismo día en que el BVerfG alemán emitía una resolución en la que, esta vez, para alivio de la Unión, rechazaba la petición de los demandantes contra la Decisión de los Recursos Propios.

13 STJUE (2020).

14 Ziller (2021).

15 Valle y Genevoix (2021); utilizando la expresión "Frexit" para caracterizar la decisión: Cassia (2021) y Turmo (2021). 
de gran alcance llevada a cabo en el ámbito de la organización y funcionamiento del poder judicial en dicho país, producida a través de diversas enmiendas legislativas entre los años 2017 y 2019. Aunque la mencionada jurisdicción constitucional avaló dicha reforma, determinados órganos jurisdiccionales remitieron diversas cuestiones prejudiciales preguntándose si algunas de esas modificaciones legislativas eran conformes con el Derecho de la UE, en particular en atención al art. 19.1 TUE y la Decisión de la Comisión 2006/928/CE, de 13 de diciembre, por la que se estableció, con motivo de la adhesión de Rumanía a la UE, un mecanismo de cooperación y verificación (CVM) de los avances logrados por este país para cumplir con indicadores concretos en materia de reforma judicial y lucha contra la corrupción.

La respuesta del TJ mediante la Sentencia Asociaţia 'Forumul Judecătorilor Din România' v Inspecţia Judiciară, de 18 de mayo de 2021, en la que se reconocía el carácter vinculante de la mencionada Decisión 2006/928/CE, vino a resaltar, entre otras cuestiones, dos ideas ligadas al principio de primacía del Derecho de la UE que ahora nos interesa destacar. Por una parte, el Tribunal volvió a señalar la idea marco que viene reiterando insistentemente de que, en virtud de dicho principio, la invocación por un Estado miembro de normas de Derecho nacional, incluso de orden constitucional, no puede menoscabar la unidad y la eficacia del Derecho de la Unión ${ }^{16}$. Y por otra, de forma más concreta e incisiva, enfatizó que:

"el principio de primacía del Derecho de la Unión debe interpretarse en el sentido de que se opone a una regulación de rango constitucional de un Estado miembro, según la interpretación de su tribunal constitucional, a tenor de la cual un tribunal de rango inferior no está facultado para dejar sin aplicar, por su propia autoridad, una disposición nacional en el ámbito de aplicación de la Decisión 2006/928, que considera, a la luz de una sentencia del Tribunal de Justicia, contraria a dicha Decisión o al art. 19, apartado 1, párrafo segundo, del TUE” (par. 252).

Veinte días más tarde, el TC rumano señaló por unanimidad, mediante resolución de 8 de junio de 2021, que la respuesta del TJ autorizando a inaplicar de oficio una disposición nacional considerada contraria a la mencionada Decisión 2006/928 de la Comisión "no tiene fundamento en la Constitución rumana", puesto que los informes del CVM elaborados sobre la base de esa Decisión "no constituyen normas de Derecho de la UE que el juez nacional deba aplicar de forma prioritaria, desatendiendo la norma nacional". De forma contraria a lo señalado por el TJ, el TC rumano afirmará que "los informes de la CVM no establecen normas jurídicas y, por tanto, no son susceptibles de entrar en conflicto con el Derecho nacional" ${ }^{17}$. El Tribunal Constitucional apuntará, asimismo, que la primacía aplicativa del Derecho europeo recogida en el art. 148 de la Constitución (que regula las relaciones entre el Derecho nacional y el Derecho de la UE, y en el que se fundamenta la

16 STJUE 2021, par. 245.

17 TC de Rumanía (2021, par. 78). 
competencia del juez nacional para ignorar la legislación interna contraria al Derecho de la Unión ${ }^{18}$ ) "también se aplica al Tribunal Constitucional", pero que, sin embargo, "no debe percibirse como la eliminación o el desconocimiento de la identidad constitucional nacional". "La garantía de un núcleo de identidad sustantiva de la Constitución rumana [...] no debe relativizarse en el proceso de integración europea. En virtud de esa identidad constitucional, el Tribunal Constitucional está facultado para garantizar la primacía de la Ley Fundamental en Rumanía” (par. 74). El Tribunal aclara, también, que la mencionada cláusula constitucional se refiere a la primacía del Derecho de la UE sobre la legislación infraconstitucional y que la Ley Fundamental "mantiene su posición jerárquicamente superior". De manera que, "el art. 148 de la Constitución no da prioridad al Derecho de la UE sobre la Constitución rumana, por lo que un tribunal nacional no está facultado para examinar la conformidad de una disposición de Derecho nacional, declarada constitucional a la luz del art. 148 de la Constitución, con las disposiciones del Derecho de la UE" ${ }^{19}$.

Siguiendo con la secuencia temporal, puede ser también interesante traer a colación que, un mes más tarde de haber enarbolado el principio de primacía sobre la jurisdicción constitucional rumana, el TJ tendrá ocasión de precisar los efectos de dicho principio sobre las decisiones de una jurisdicción constitucional en el asunto Latvijas Republikas Saeima 20. Se trata de una resolución en la que, tras reiterar otra vez su jurisprudencia según la cual "no puede admitirse [en virtud del mencionado principio] que normas de Derecho nacional, aun si son de rango constitucional, menoscaben la unidad y la eficacia del Derecho de la Unión”, recordará que, aun suponiendo que consideraciones imperiosas de seguridad jurídica puedan conducir, con carácter excepcional, a suspender provisionalmente el efecto de exclusión que ejerce una norma de la Unión directamente aplicable sobre el Derecho nacional contrario a ella, "los requisitos de tal suspensión solo los puede establecer el Tribunal de Justicia” ${ }^{21}$. Y en este sentido, resolverá la remisión prejudicial en cuestión, planteada por el TC de la República de Letonia, afirmando que:

18 El segundo apartado de dicho artículo señala que "como consecuencia de la adhesión, las disposiciones de los tratados constitutivos de la Unión Europea, así como las demás normas comunitarias obligatorias, prevalecerán sobre las disposiciones contrarias de las legislaciones nacionales, de conformidad con las disposiciones del acta de adhesión"; por su parte, el cuarto apartado establece que "el Parlamento, el presidente de Rumanía, el Gobierno y la autoridad judicial garantizarán el cumplimiento de las obligaciones derivadas del Acta de Adhesión y de las disposiciones del apartado".

${ }_{19}$ Par. 76. Para un análisis de la Sentencia del TJUE, entre otros: Tănăsescu y Selejan-Gutan (2021, 2 jun.) y Dimitrovs y Kochenov (2021). Sobre la Sentencia del Tribunal Constitucional de Rumania: Selejan-Gutan (2021, 18 jun.).

20 STJUE (2021).

21 Par. 135, recordando, en este sentido, la previa STJUE Winner Wetten (2010), párs. 61 y 67. 
"el principio de primacía del Derecho de la Unión debe interpretarse en el sentido de que se opone a que el tribunal constitucional de un Estado miembro que conoce de un recurso interpuesto contra una normativa nacional que, a la luz de una resolución del Tribunal de Justicia dictada tras la remisión prejudicial correspondiente, resulta ser incompatible con el Derecho de la Unión decida, con arreglo al principio de seguridad jurídica, que se mantienen los efectos jurídicos de dicha normativa hasta la fecha en que ese tribunal constitucional dicte una sentencia que resuelva definitivamente sobre tal recurso de inconstitucionalidad" (par. 137).

(d) El último y probablemente más intenso desafío que ha sufrido el principio de primacía es el protagonizado por el Trybunat Konstytucyjny (Tribunal Constitucional) de la República de Polonia, en un contexto relativo, también aquí, a diversas y conflictivas reformas referidas a la organización judicial. En efecto, el 14 de julio de 2021 el TC polaco dictaminó que las medidas provisionales emitidas por el del TJUE que afectaban a la organización de los tribunales polacos no eran compatibles con la Constitución polaca y no eran vinculantes $^{22}$. El 16 de julio de 2021, aludiendo a esta Sentencia, la presidenta primera del Tribunal Supremo de Polonia revocó una decisión previa del anterior presidente primero (en funciones) del Tribunal Supremo ${ }^{23}$ por la que se aplicaba un Auto del TJUE de 8 de abril de 2020 para suspender las actividades de la Sala Disciplinaria del Tribunal Supremo en casos disciplinarios contra jueces ${ }^{24}$.

Conviene tener presente que, con antelación a la decisión del Tribunal Constitucional, y atendiendo la demanda de medidas provisionales formulada por la Comisión Europea en el marco de un recurso por incumplimiento contra Polonia ante el Tribunal de Justicia activado por la propia Comisión, este Tribunal había acogido mediante el mencionado Auto de 8 de abril de 2020 las medidas cautelares solicitadas, ordenando a Polonia suspender inmediatamente la aplicación de las disposiciones nacionales sobre los poderes de la Sala Disciplinaria del Tribunal Supremo con respecto a los casos disciplinarios relacionados con jueces ${ }^{25}$, a la espera de que se dictara sentencia sobre el fondo. Esta sentencia de cierre sobre el caso se dictó el 15 de julio de 2021, un día después de que el TC polaco dictara - previendo su contenido a expensas del señalado Auto cautelar- su desafiante Sentencia arriba mencionada. El Tribunal de Luxemburgo declaró en su resolución que la República de Polonia había incumplido las obligaciones que le incumbían en virtud del art. 19.1 (2) TUE (entre otras razones, al no garantizar la independencia

22 Sentencia TC Polonia (1921, 14 jul.), a demanda interpuesta por la Sala de Disciplina del Tribunal Supremo.

${ }^{23}$ Decisión de 5 de mayo de 2020 (55/2020).

24 https://www.sn.pl/en/actualities/SitePages/Actualities.aspx?ItemSID=31Od89abd2-8bba-4029-999a-feb44dcfa88b\&ListName=current_events

25 Auto Comisión / Polonia (2020). Sobre el Auto, así como respecto de las previas Sentencias en los anteriores recursos por incumplimiento contra Polonia (en materia de independencia judicial y Estado de Derecho), entre otros: Pech y Kochenov (2021) y Ugartemendia Eceizabarrena (2021). 
e imparcialidad de la ya mencionada Sala de Disciplina del Tribunal Supremo) y las que le concernían en atención al art. 267 TFUE (al permitir que el derecho de los juzgados y tribunales a presentar solicitudes de decisión prejudicial al Tribunal de Justicia de la Unión Europea se viera restringido por la posibilidad de iniciar un procedimiento disciplinario) ${ }^{26}$.

Es interesante recordar en este contexto el segundo Informe de la Comisión sobre el Estado de Derecho en la Unión Europea, publicado el 20 de julio de 2021, donde se reconoce que, al igual que se han producido avances positivos en diversos campos y países en relación con el informe anterior (septiembre 2020), existen también cuestiones que deben mejorar. En este sentido, la Comisión muestra, entre otras cosas, una grave preocupación respecto a las consecuencias de las reformas judiciales llevadas a cabo en Polonia, recal-

26 STJUE Comisión / Polonia (2021).

El 14 de julio se emitió, asimismo, el Auto de la vicepresidenta del TJUE (C-204/21 R) por el que, aceptándose la demanda de medidas provisionales de la Comisión Europea (interpuesta el 1 de abril de 2021), se establece que la República de Polonia está obligada, inmediatamente y hasta que se dicte la sentencia que dará por terminado el procedimiento en el caso (asunto C-204/21, también relativo al régimen disciplinario de los jueces) a suspender la aplicación de varias disposiciones nacionales introducidas por una Ley, de 20 de diciembre de 2019, por la que se modifica la Ley de Organización de la Jurisdicción Ordinaria, la Ley del Tribunal Supremo y algunas otras leyes. El Auto del Tribunal de Justicia, por lo que ahora interesa, recordará que, "habida cuenta de los efectos del principio de primacía del Derecho de la Unión, la República de Polonia no puede invocar válidamente el conflicto entre las disposiciones del Derecho nacional, incluido el Derecho constitucional, y los efectos de la aplicación de una medida provisional ordenada por el Tribunal de Justicia [...], ni el perjuicio para los intereses de dicho Estado miembro que [...] se derivaría de la aplicación de tal medida. En cualquier caso, dicho perjuicio, aunque se constatara, no puede prevalecer sobre el interés general de la Unión en el buen funcionamiento de su ordenamiento jurídico" (apdo. 191).

Conminada la República de Polonia a explicar a la Comisión Europea el modo en que iba a cumplir con las mencionadas dos sentencias del TJUE sobre el régimen disciplinario de jueces (C-791/19 y C-204/21), el Gobierno polaco señaló que la Sala Disciplinaria del Tribunal Supremo polaco sería disuelta en su forma actual "como parte de una nueva reforma del sistema judicial, que comenzará en los próximos meses" ( $\sin$ que quedara claro qué iba a ser de los casos pendientes ni qué iba a implicar la mencionada reforma); al respecto, criticando el carácter cosmético de la iniciativa: Sadurski [2021]); no obstante, el gobierno polaco también pidió que la Unión renunciara a su Auto de medidas provisionales (C-204/21 R) puesto que ignoraba la primacía del Derecho de la UE en este asunto. El 6 de octubre de 2021 se dictó el Auto del vicepresidente del TJUE (C-204/21 R-RAP) por el que se rechaza el recurso de Polonia de revocar el ATJUE de 14 de julio, señalándose además que la Sentencia del TC polaco (de 14 de julio de 2021) declarando que tales medidas provisionales son contrarias al orden constitucional de Polonia no altera en modo alguno lo dispuesto en el ATJUE del 14 de julio. Al hilo de lo señalado, la Comisión entiende que Polonia no ha cumplido ni con el Auto TJUE C-204/21 R ni con la STJUE C-791/19, de manera que ha solicitado al TJ que imponga frente al incumplimiento de las medidas cautelares apuntadas una multa diaria de medio millón de euros, y ha iniciado el procedimiento para acreditar el incumplimiento de la citada sentencia. 
cando que, según el TJ, "el régimen disciplinario de los jueces en Polonia no es compatible con el Derecho de la UE" (citando la arriba señalada Sentencia del TJ de 15 de julio de 2021); o apuntando que "las preocupaciones sobre la independencia y legitimidad del Tribunal Constitucional [polaco] aún no se han resuelto, como lo confirmó el Tribunal Europeo de Derechos Humanos al concluir que la composición del Tribunal Constitucional no cumplía con el requisito de "un tribunal establecido por ley"' 27.

En este turbulento ambiente jurisdiccional con respecto a la República de Polonia, se acaba de conocer la respuesta de su Tribunal Constitucional a la cuestión presentada por el primer ministro Mateusz Morawiecki, en marzo de 2021, para que dictamine acerca de la supremacía de la Constitución polaca sobre el Derecho de la UE. En efecto, tras haber pospuesto la decisión por cuatro veces, el TC ha dictado Sentencia al respecto el 7 de octubre de $2021^{28}$ y ha decidido ahora que determinadas disposiciones centrales del Derecho primario de la UE (p.e. arts. 1y 19 del TUE) son incompatibles con la Constitución de Polonia, negando de forma clara, abierta y desafiante el principio de primacía del Derecho de la Unión en la medida en que se oponga a la Constitución de Polonia (según esta es entendida por su TC) ${ }^{29}$.

(e) Veamos finalmente el contrapunto maltés: en el marco de las recientes resoluciones jurisdiccionales que vienen mostrando una posición desafiante contra el principio de primacía del Derecho de la UE sobre la Constitución nacional, aparece como modesto pero digno contrapunto la posición marcada por el Tribunal Constitucional de Malta (rectius: Tribunal de lo Civil, Sala Primera, actuando en funciones de Tribunal Constitucional) en el asunto de la Sentencia del TJUE Repubblika/II-Prim Ministru. Se trata de otro caso relacionado con la mencionada primacía también activado por una jurisdicción constitucional a través del planteamiento de una cuestión prejudicial, que versa asimismo sobre materia de administración de justicia nacional. Lo destacable de este asunto para nuestro tema reside en que, en este caso, tanto esa jurisdicción constitucional como el TJ asumen dicha primacía hasta el punto de activar y ejercer, respectivamente, con normalidad, una suerte de control de "europeidad" de algunas normas de

27 (Con mención de la STEDH Xero Flor c. Polonia, 2021) Comunicación de la Comisión al Parlamento Europeo y el Consejo, acerca del Informe sobre la situación del Estado de Derecho en la Unión Europea (2021: 8). Siguiendo con las menciones a la jurisprudencia de Estrasburgo, es asimismo remarcable la Sentencia del TEDH en el asunto Reczkowicz c. Polonia (2021), en la que se condena a Polonia por vulneración del derecho a un "tribunal establecido por la ley" debido a graves irregularidades en el nombramiento de los jueces de la Sala de Disciplina del Tribunal Supremo y en la que la actuación del TC en el caso no sale, precisamente, muy bien parada.

28 Sentencia TC Polonia (2021, 7 oct.), sobre la evaluación de la conformidad con la Constitución polaca de determinadas disposiciones del Tratado de la Unión Europea.

${ }^{29}$ La Sentencia ha sido dictada en fase de corrección de pruebas del presente trabajo. Para más detalles acerca del contenido de la misma: https://trybunal.gov.pl/ en/hearings/judgments/art/11662-ocena-zgodnosci-z-konstytucja-rp-wybranych-przepisow-traktatu-o-unii-europejskiej Para algunas interesantes valoraciones al respecto (incluidas diversas consideraciones sobre un "legal Polexit"), véase, por ej.: Steinbeis (2021, 9 oct. y 15 oct., y la doctrina allí señalada). 
la Constitución introducidas a través de una previa reforma constitucional. En efecto, mediante reforma constitucional de 2016 Malta introdujo en su Constitución de 1964 la facultad del primer ministro para seleccionar — discrecionalmente- miembros de la judicatura entre los candidatos aprobados por el Comité de Nombramientos Judiciales, correspondiendo luego el nombramiento formal al presidente de la República. En diciembre de 2019, en un contexto muy delicado, de gran preocupación de la Unión acerca del respeto del Estado de Derecho y la independencia judicial en determinados Estados miembros (Polonia, Hungría, Rumanía, o la propia Malta), el Tribunal maltés remitió al TJ una cuestión prejudicial en la que le planteaba si hay que considerar aplicable el Derecho de la Unión [en concreto el relativo a la "tutela judicial efectiva" (arts. 19.1[2] TUE y 47 de la CDFUE)] "a efectos de determinar la validez jurídica" de esa normativa constitucional incorporada en 2016 que daba la susodicha facultad al primer ministro (arts. 96, 96. ${ }^{a}$ y 100). Se preguntaba, además, si, de ser afirmativa la respuesta, esa facultad constitucional del primer ministro era o no conforme con el DUE, y si, de no serlo, la incompatibilidad alcanzaría también a los nombramientos ya efectuados. El TJ sentenció, el 20 de abril de 2021, que el DUE no se opone a la normativa constitucional maltesa en cuestión. En cualquier caso, y pese a que el Tribunal de Justicia no constató ni estimó esa incompatibilidad, no es difícil percibir el destello que producen en este tema los siguientes dos aspectos: en primer lugar, que fue la propia jurisdicción constitucional maltesa la que activó el control de europeidad sobre el respeto del Derecho de la Unión por parte de las disposiciones constitucionales señaladas, introducidas vía reforma en 2016; y en segundo lugar, que el TJ llevó a cabo con normalidad ese control jurisdiccional $^{30}$.

\section{EL CONTROL Y LOS LÍMITES DE LA PRIMACÍA}

Como es conocido, del mismo modo que una Constitución no admite, dentro del ordenamiento interno, una norma contraria a la misma, tampoco el Derecho de la UE tolera que se pueda oponer al mismo ninguna norma nacional, ni siquiera las de rango constitucional (sea originaria o incorporada vía reforma constitucional), siendo indiferente a estos efectos que la norma europea contrapuesta sea Derecho originario o Derecho derivado de la Unión ${ }^{31}$. En este sentido, la UE parte de una concepción absoluta de la primacía del

30 STJUE Repubblika/II-Prim Ministru (2021). Sobre la Sentencia, entre otros: Kochenov y Dimitrovs (2021, 28 abr.). Por lo demás, puede también ser interesante el dato relativo a que, antes de que se emitiera la citada Sentencia -y las Conclusiones del Abogado General G. Hogan (2020)_, Malta ya había vuelto a reformar la Constitución revisando (¿preventivamente?) entre otras, precisamente, las normas señaladas sobre las que se había planteado la petición prejudicial (lo cual no impidió que esta siguiera su curso), de manera que, ahora, es el Comité de Nombramientos Judiciales el que actúa proponiendo los candidatos más adecuados al presidente.

31 Con claridad desde la Sentencia del Tribunal de Justicia en el asunto Internationale Handelsgesellschaft (1970, par. 3); posición que sigue manteniéndose en atención a salvaguardar la unidad y la eficacia del Derecho de la Unión, como hemos podido 
Derecho de la Unión, primacía de "todo" el Derecho de la Unión (originario o derivado), sobre toda norma nacional, cualquiera que sea el rango de esta, incluso si se trata de una norma constitucional.

Por su parte, los Estados miembros, que participan en la integración europea y asumen el Derecho de la Unión a través de un "poder de integración" reconocido en la Constitución, sea en cláusulas generales o específicas, no muestran ningún problema en aceptar esa primacía europea respecto a las normas infraconstitucionales. En cambio, pueden surgir dificultades para el reconocimiento del principio de primacía cuando es la Constitución nacional la que se enfrenta u opone a la primacía del DUE (o viceversa). En este sentido, muchos Estados de la Unión han dejado claro, con antelación a los casos que se acaban de describir, que no asumen ese principio de primacía en términos absolutos por cuanto reconocen también la existencia de condiciones o límites materiales irreductibles frente a la misma. Se conciben, valga la redundancia, como límites a la limitación de la soberanía nacional que implica el proceso de integración europea y el Derecho de la Unión, también conocidos por ello como "contralímites". Volveremos sobre ello en este apartado, un poco más adelante.

En cualquier caso, desde la perspectiva del Derecho de la Unión, una vez constatado el conflicto normativo entre norma constitucional nacional y Derecho de la Unión, el principio de primacía exige que este se imponga sobre aquella, obligando a que la norma constitucional contrapuesta sea removida (lo cual se realiza, como podremos ver infra en el apartado cuatro, a través de diversos mecanismos). A estos efectos, lo que nos interesa ahora es analizar de qué manera se controla y se constata por parte de la UE la vulneración del principio de primacía que es llevada a cabo sobre la base de normas constitucionales nacionales.

\subsection{El control del respeto de la primacía del Derecho de la Unión}

Para precisar esta cuestión, conviene advertir, tal y como hace la doctrina especializada, que el principio de primacía del Derecho de la Unión tiene o presenta dos vertientes, una normativa y otra aplicativa, las cuales se manifiestan con claridad en caso de conflicto entre una norma europea y otra nacional ${ }^{32}$. Se trata de un contenido bidimensional que conduce, como veremos, a la posibilidad de realizar un doble tipo de control de europeidad acerca del respeto del DUE, en nuestro caso del respeto por parte de las normas constitucionales. Por una parte, en su dimensión aplicativa, la primacía se manifiesta como preferencia o prevalencia aplicativa, y se concreta cuando,

observar en la jurisprudencia del TJUE señalada al comienzo de este trabajo (cuarta nota).

32 Véase Sarmiento (2020: 332-333). 
en caso de conflicto, el órgano estatal encargado de aplicar el Derecho de la Unión (el órgano jurisdiccional nacional) inaplica la norma nacional contrapuesta a la norma europea. Esta primacía aplicativa se expresa, pues, como un control de la aplicabilidad o eficacia de la norma nacional incompatible, sin perjuicio de que el Estado esté, además, obligado a remover o depurar del ordenamiento jurídico la norma nacional constatada como opuesta al Derecho de la Unión. Como recuerda la Sentencia del TJ A.B. y otros:

"los efectos que se asocian al principio de primacía del Derecho de la Unión se imponen a todos los órganos de un Estado miembro, sin que puedan oponerse a él, en particular, las disposiciones internas relativas al reparto de las competencias judiciales, incluidas las de rango constitucional" (2021, par. 148) ${ }^{33}$.

Y en esta línea, "el principio de primacía del Derecho de la Unión debe interpretarse en el sentido de que obliga al órgano jurisdiccional remitente a dejar inaplicadas" las normas del ordenamiento jurídico nacional que se acrediten como contrarias al Derecho de la Unión, "sean de origen legislativo o constitucional" 34 (regla que también se señala en la reciente y ya citada Sentencia Asociaţia 'Forumul Judecătorilor Din România' v Inspecţia Judiciară ${ }^{35}$ ).

Pero la primacía no solo se manifiesta a nivel aplicativo, también lo hace en su vertiente normativa. En esta su proyección se concreta en que los Estados miembros no pueden, en virtud de las obligaciones contraídas por ellos mismos en el marco de la Unión, oponer sus normas internas -ni siquiera las de rango constitucional - para no cumplir con esas obligaciones establecidas en el Derecho de la Unión. ${ }^{36}$

33 Y continúa la Sentencia: "En efecto, según reiterada jurisprudencia, resulta inadmisible que normas del Derecho nacional puedan menoscabar la unidad y la eficacia del Derecho de la Unión, aunque se trate de normas de rango constitucional".

34 STJUE A.B. y otros (2021, párs. 150 y 169).

35 Afirmando que "en caso de infracción probada del art. 19 TUE, apartado 1, párrafo segundo, o de la Decisión 2006/928, el principio de primacía del Derecho de la Unión obliga al órgano jurisdiccional remitente a no aplicar las disposiciones de la causa, ya sea que sean de origen legislativo o constitucional [...]" (2021, par. 251).

Por lo demás, el mecanismo de la inaplicación de la norma nacional contraria entra en juego una vez que haya fallado el instrumento de la interpretación conforme. Como señala el TJ, es entonces, cuando no haya resultado posible interpretar la normativa nacional conforme a las exigencias del Derecho de la Unión, cuando el juez nacional encargado de aplicar, en el ámbito de su competencia, las disposiciones del Derecho de la Unión tendrá la obligación de garantizar la plena eficacia de tales disposiciones, dejando inaplicada, si fuera necesario, y por su propia iniciativa, cualquier disposición contraria de la legislación nacional, aun posterior, sin que deba solicitar o esperar su previa eliminación por vía legislativa o mediante cualquier otro procedimiento constitucional [véanse, en este sentido, las SSTJUE: Minister for Justice and Equality y Commissioner of An Garda Síochána (2018, par. 35); Poplawski II (2019, párs. 58 y ss.); La Quadrature du Net y otros (2020, par. 215); o la arriba citada Sentencia de la Asociación de jueces rumanos (par. 247)].

36 Así se constata, por ejemplo, ya en las SSTJUE: Comisión c. Italia (1978, par. 21); o Comisión c. Bélgica (1980, par. 15). Más recientemente, entre otras, en las SSTJUE: Comisión c. Alemwania (2007, par. 38); o Comisión c. Hungría (2014, par. 35). Re- 
En esta dimensión el conflicto entre norma europea y norma nacional se expresa como un conflicto abstracto, y el mecanismo para garantizar la primacía europea es el recurso por incumplimiento ante el Tribunal de Justicia, un instrumento cuyo objeto es única y exclusivamente declarar la compatibilidad o incompatibilidad de una actuación (u omisión) estatal en relación con el Derecho de la Unión en cuanto a su cumplimiento, sin entrar a declarar o constatar la (in)eficacia o (in)aplicabilidad de la misma (en realidad, a estos efectos, no es necesario siquiera que exista un litigio concreto, ni tampoco que la norma europea tenga efecto directo ${ }^{37}$ ).

Así pues, el control de europeidad de la norma constitucional nacional eventualmente contrapuesta al DUE puede aparecer como un control de su aplicabilidad en un litigio concreto, llevado a cabo por parte del juez nacional que aplica Derecho de la Unión. Pero también puede manifestarse como un control acerca del cumplimiento del Derecho de la Unión, en este caso a través del Tribunal de Justicia, a instancias de los legitimados para el recurso por incumplimiento (Comisión Europea y otros Estados miembros); esto es, un control de la norma nacional -incluso, en su caso, de una norma constitucional- llevado a cabo por entes o sujetos no pertenecientes al Estado. Conviene insistir en el hecho de que los sujetos que realizan este control del (in)cumplimiento del DUE son todos ellos entes ajenos al Estado en cuestión. Se trata, en suma, de un control externo de la norma nacional, no solo en cuanto al parámetro, sino también en cuanto a los operadores que lo activan y llevan a cabo, todos ellos entes foráneos y extraños al Estado cuya Constitución se controla ${ }^{38}$.

cuérdese, asimismo, la repetida idea (de forma significativa al menos cinco veces en lo que va de año 2021), ya señalada, de que, "en virtud del principio de primacía del Derecho de la UE, no puede permitirse que la invocación de un Estado miembro de las normas del Derecho nacional, incluso de un orden constitucional, socave la unidad y la eficacia del Derecho de la UE” (SSTJUE: A.B. y otros, par. 148; Asociaţia 'Forumul Judecătorilor Din România', par. 245; Latvijas Republikas Saeima, par. 135; W.Ż., par. 157; y en el ATJ Comisión c. Polonia, C-204/21 R-RAP, par. 24).

37 A diferencia de lo que ocurre para poder activar el recurso por incumplimiento, donde no es necesario que la norma europea contradicha o infringida tenga efecto directo, sí es imprescindible ese efecto directo a la hora de poder llevar a cabo un control de aplicabilidad de la norma nacional contraria al Derecho de la Unión (control de aplicabilidad). En efecto, tal y como el TJ confirmó no hace mucho, la obligación impuesta a las autoridades nacionales de inaplicar normas nacionales que sean contrarias a las disposiciones de la UE está condicionada al efecto directo de estas últimas. El principio de primacía no obliga a que un órgano jurisdiccional nacional tenga que abstenerse de aplicar una norma nacional incompatible con el Derecho de la Unión si la norma europea contradicha carece de efecto directo. No obstante, las autoridades de los Estados miembros -incluidos los órganos jurisdiccionales- están obligadas a efectuar, en la medida de lo posible, una interpretación conforme de su Derecho nacional que les permita garantizar un resultado compatible con la finalidad perseguida por la norma o disposición europea de que se trate [STJUE Poplawski II, cit., par. 109; al respecto, por ejemplo: Miasik y Szwarc (2021: 571 y ss.)].

38 Es interesante señalar, además, que este control respecto al cumplimiento del Derecho de la UE por parte del Estado miembro difiere notablemente respecto al con- 
Hay que constatar que, obviamente, el incumplimiento no desaparece por el hecho de que el Estado - por la razón que sea-decida, en su caso, ignorar ese conflicto normativo y seguir manteniendo la norma constitucional. Dicho de otra manera, no reconocer la primacía del Derecho de la Unión no hace desaparecer el (eventual) incumplimiento ni el control al respecto, el cual es realizado, como se ha señalado, por el TJUE.

\subsection{Los límites del principio de primacía}

Llegados aquí hay que señalar que la primacía del Derecho de la Unión y, por tanto, el control de europeidad relativo a si las normas nacionales respetan dicho principio tienen también, como ya se ha adelantado, sus límites. Ahí están, por un lado, los límites previstos por el propio Derecho de la Unión, deducibles, de forma genérica, de los arts. 4 y 5 del TUE. A tenor de ellos el DUE no puede regir ni, por tanto, primar en el ámbito de las competencias no atribuidas a la Unión, ni en contra del principio de cooperación leal con los Estados, o sin respetar la identidad nacional y/o constitucional de los Estados

trol del cumplimiento de lo acordado que pueda darse en el Derecho internacional. Como recuerda la profesora Paz Andrés Sáenz de Santa María, en la estructura del Derecho internacional de carácter relacional entre Estados, la tutela jurídica frente al incumplimiento de un Estado infractor se lleva a cabo de Estado a Estado "a través de un mecanismo de autotutela"; por su parte, en la estructura del Derecho internacional institucional, en el ámbito de las organizaciones internacionales creadas por los Estados, la situación cambia, ya que la existencia de esas organizaciones "permite la aparición de una tutela centralizada u organizada, mediante sanciones adoptadas por un órgano de una institución internacional" (2018; cap. I.III.1). Pero el sistema del recurso por incumplimiento propio de la Unión Europea muestra especificidades respecto al sistema internacional, donde el cumplimiento de las obligaciones se tutela con el juego del principio de reciprocidad, o a través, en su caso, de una institución internacional. Según destaca Jacqué, dicho sistema permite a la Comisión y a los Estados miembros (ex arts. 258 y 259 TFUE, respectivamente) solicitar al Tribunal de Justicia de la Unión que declare que un Estado miembro no ha cumplido con sus obligaciones. "La constatación de la infracción o incumplimiento no tiene otro efecto inmediato que el de imponer al Estado concernido cumplir con sus obligaciones. El acto en cuestión no se anula". No obstante, "los tribunales nacionales que se rigen por la primacía del Derecho de la Unión deberán deducir los efectos de tal constatación, tanto en lo que respecta a la aplicación del acto como desde el punto de vista de la responsabilidad del autor del incumplimiento". De manera que el sistema preserva así, en apariencia, al Derecho nacional de una intervención del Tribunal de Justicia y hace que la decisión sea más aceptable, ya que dependerá de las autoridades judiciales nacionales sacar las consecuencias prácticas de la infracción al aplicar el Derecho de la Unión según resulte de la interpretación realizada por el Tribunal de Luxemburgo (2010: 664-665). Es posible recordar, por cierto, el uso que se está comenzando a dar al recurso de incumplimiento como mecanismo de tutela de los derechos fundamentales en la UE. Al respecto, in extenso, Rodríguez-Izquierdo Serrano (2018: 948-949; o 2021: 214 y ss.). 
miembros ${ }^{39}$. Sea como fuere, allá donde no debe regir la primacía, tampoco debe existir un control para garantizarla.

Por otro lado, es conocido que, más allá de la Unión, también los Estados han venido trazando límites al principio de primacía como consecuencia de la consideración de que la atribución estatal de poderes y de soberanía a la Unión no es ilimitada, sino que está sujeta al respeto de los principios superiores del ordenamiento constitucional, incluidos los derechos inalienables de la persona. Principios que se identifican, muchas veces, con la identidad constitucional (nacional).

Inicialmente esos límites fueron explicitados por la jurisprudencia constitucional de algunos países (como Alemania e Italia), pasando luego a formalizarse en algunos textos constitucionales. En todo caso, la mayoría de los Tribunales Constitucionales (o, en su caso, Supremos de los Estados miembros) entiende que la primacía de aplicación del Derecho de la Unión no se aplica sin límites, sino que está restringida, expresado ahora de forma muy resumida, por los límites que derivan del núcleo principial de la Constitución nacional ${ }^{40}$.

Esta visión o panorama limitante es, como es conocido, previa a las desafiantes sentencias que hemos descrito supra en el segundo apartado. Ahí está el caso del TC alemán, que viene identificando como límite de identidad constitucional el respeto de los Derechos Fundamentales (con las conocidas sentencias Solange I y II o la de 15 de diciembre de 2015 sobre ejecución de una euroorden en el marco de una condena en ausencia ${ }^{41}$ ); o también el límite, ligado al principio democrático, de la no actuación ultra vires de la Unión Europea (Sentencias Maastricht, Banana Market, Lisboa, Honeywell, Gauweiler o Weiss). Ahí está, asimismo, la Corte Constitucional italiana, con sus sentencias Frontini, Granital, Fragd o, más recientemente, con su Auto de remisión prejudicial en la saga Taricco ${ }^{42}$, en relación con el estándar de protección del principio de legalidad penal en materia de prescripción penal. Como es sabido, la Corte aludió a la teoría de los contralímites y sugirió veladamente que, aunque la primacía está asumida por la Corte, si esta pri-

39 Art. 4.2 TUE: "La Unión respetará la igualdad de los Estados miembros ante los Tratados, así como su identidad nacional, inherente a las estructuras fundamentales políticas y constitucionales de estos, también en lo referente a la autonomía local y regional. Respetará las funciones esenciales del Estado, especialmente las que tienen por objeto garantizar su integridad territorial, mantener el orden público y salvaguardar la seguridad nacional. En particular, la seguridad nacional seguirá siendo responsabilidad exclusiva de cada Estado miembro".

40 Cabe apuntar que también se englobarían dentro de los límites a la primacía aquellas cláusulas constitucionales previstas como límites materiales a la reforma (cláusulas de intangibilidad o cláusulas de eternidad), pues si un límite es irreductible a la revisión constitucional interna lo sigue siendo también, de alguna manera, ante la entrada de una norma supraestatal.

41 Sentencia TC Alemán - Sala 2. ${ }^{\text {(2015). }}$

42 Auto Corte Constitucional italiana (2017). 
macía obligara a ir (como parecía deducirse de la STJUE Taricco $I^{43}$ ) contra los principios supremos del orden constitucional o los derechos inalienables, entonces declararía ilegítima la ley nacional que autorizaba la ratificación de los Tratados, en la parte en que lo permitiera (en el caso, el art. 325 TFUE). A resultas de ello el TJ terminó "flexibilizando" algo el carácter absoluto e incondicional de la primacía (con la Sentencia M.A.S. y M.B. 44, también conocida como Taricco $I I$ ), dando a entender que el juez nacional puede no inaplicar normas nacionales contrarias si ello lleva a vulnerar el principio de legalidad u otro Derecho Fundamental ${ }^{45}$.

Hay que mencionar, igualmente, que esta posición, la de establecer límites, es también la posición mantenida por los Tribunales constitucionales (o Supremos) de otros países como la República Checa, Dinamarca, Francia, Estonia, Lituania, etc. ${ }^{46}$, o, más recientemente, la del TC de Portugal en la Sentencia de 15 de julio de $2020^{47}$, así como las ya señaladas de los tribunales constitucionales de Rumanía y Polonia; y esta es, asimismo, la postura del TC español en la DTC 1/2004 o en la STC 26/14 ${ }^{48}$.

\section{LAS SALIDAS A LA VULNERACIÓN DEL PRINCIPIO DE PRIMACÍA}

Todo el entramado limitante del principio de primacía que se acaba de mencionar no debe hacer perder de vista que, si existe un conflicto entre Derecho de la Unión y norma constitucional, debe arbitrarse una salida para no enquistar el mismo, con independencia de que la norma constitucional con-

43 STJUE (2015).

44 STJUE (2017).

45 Sobre la posición de la Corte italiana: Alonso García (2021a).

46 Puede verse una relación de las Sentencias al respecto de los respectivos Tribunales constitucionales en la arriba mencionada Sentencia del TC alemán de 15 de diciembre de 2015, par. 47. Véase, también, entre otros: Grabenwarter, Huber, Knez y Ziemele (2021: 44-45), Sarrión Esteve (2020: espec. 37 y ss.), Paris (2028: 206 y ss.).

47 Sobre el tema de los límites al control de europeidad, véase, también, por ejemplo: Ugartemendia Eceizabarrena y Donaire Villa (2019: 258 y ss.).

48 “...] [L]a operación de cesión del ejercicio de competencias a la Unión Europea y la integración consiguiente del Derecho comunitario en el nuestro propio imponen límites inevitables a las facultades soberanas del Estado, aceptables únicamente en tanto el Derecho europeo sea compatible con los principios fundamentales del Estado social y democrático de Derecho establecido por la Constitución nacional. Por ello la cesión constitucional que el art. $93 \mathrm{CE}$ posibilita tiene a su vez límites materiales que se imponen a la propia cesión. Esos límites materiales, no recogidos expresamente en el precepto constitucional, pero que implícitamente se derivan de la Constitución y del sentido esencial del propio precepto, se traducen en el respeto de la soberanía del Estado, de nuestras estructuras constitucionales básicas y del sistema de valores y principios fundamentales consagrados en nuestra Constitución, en el que los derechos fundamentales adquieren sustantividad propia (art. 10.1 CE), [...]" (Declaración del TC 1/2004, FJ 2; igualmente: STC 26/2014, FJ 3). 
trapuesta encarne o no, a juicio del Estado miembro correspondiente, una parte de su identidad constitucional. En este sentido, las salidas plausibles son dos: en primer lugar, la vía interpretativa; y, en segundo lugar, si esta no funciona, la vía de la reforma formal. Al margen de estas dos posibilidades, restarían otras como la contumacia en el choque constitucional y en el incumplimiento y/o la salida de la Unión.

\section{(A) La salida de la interpretación constitucional conforme al Derecho de la Unión}

El primer mecanismo al que hay que acudir para solventar el conflicto es, como se ha dicho, la "interpretación conforme", en este caso la interpretación de la Constitución nacional "conforme" al Derecho de la Unión Europea, o lo que es lo mismo, la realización de una lectura pro unione de la Constitución nacional, de la disposición constitucional en cuestión, por parte de su supremo intérprete (hasta el límite de la interpretación contra constitutionem), una interpretación que elimine o depure las interpretaciones contrarias al Derecho de la Unión.

Así sucedió, por ejemplo, con la posición del Tribunal Constitucional checo en su Sentencia de 3 de mayo de 2006 (referida a la Euroorden), cuando constata que "del art. 1, párrafo 2 de la Constitución [la República Checa respetará sus obligaciones bajo el Derecho internacional], junto con el principio de cooperación proclamado por el art. 10 TCE [actual 4.3 TUE], se desprende el principio constitucional según el cual las disposiciones nacionales, incluida la Constitución, deben interpretarse en la medida de lo posible de conformidad con el proceso de integración europea y la cooperación entre órganos de la Unión y de los Estados miembros". Consecuentemente, concluirá el Tribunal, "en la medida en que existan diversas interpretaciones de la Constitución posibles de acuerdo con los métodos nacionales de interpretación, pero solo alguna permita a la República Checa cumplir con las obligaciones contraídas en cuanto miembro de la Unión Europea, debe ser esa interpretación la que ha de escogerse, y no aquella otra que entorpecería dicho cumplimiento". También pueden mencionarse como ejemplos significativos la Sentencia del Tribunal Constitucional de Polonia de 11 de mayo de 2005, referida a la ratificación del Tratado de Adhesión a la UE, o la de la jurisdicción constitucional de la República de Lituania en una Sentencia de 24 de enero de 2014, relativa al derecho a acuñar moneda del art. $125^{49}$.

49 Sobre los casos señalados, por ejemplo: Ugartemendia Eceizabarrena y Donaire Villa (2019:202-204). Es también interesante apuntar que la Declaración 1/1992 del TC español llegó a la conclusión de que la reforma constitucional (del art. 13.2 CE) era la única vía para solventar el conflicto existente tras constatar que ese conflicto era "irreductible por vía de la interpretación" (1992, FJ 4. ${ }^{\circ}$ ). Ahí está, igualmente, la STC 26/2014 recaída tras la Sentencia Melloni del TJUE (2013), a raíz del planteamiento de la primera remisión prejudicial planteada por el propio TC español (mediante ATC 
Por otro lado, debe señalarse asimismo que la vía interpretativa todavía puede dar otra modalidad de solución del conflicto, en concreto a través de una interpretación "flexible" por parte del TJ del principio de primacía en el caso en cuestión. Se trataría de una actividad o posición interpretativa similar a la línea marcada en el ya mencionado asunto Taricco II, y que podría ser particularmente operativa cuando, a modo de invitación al diálogo jurisdiccional, la correspondiente jurisdicción constitucional hace llegar al TJ, vía remisión prejudicial, que el conflicto en cuestión, si bien es relativo al respeto del principio de primacía del Derecho de la Unión, lo es también a normas constitucionales que contienen elementos normativos fundamentales o relativos a la identidad constitucional del Estado miembro (y/o de las tradiciones constitucionales comunes y de la jurisprudencia del TEDH) que es aconsejable no soslayar. Puestos en esta tesitura, no es descartable que el conflicto tenga alguna posibilidad de ser encauzado hacia su solución con la ayuda de la "correcta” interpretación del Derecho de la Unión por parte del TJ ${ }^{50}$.

86/2011). La mencionada STC 26/2014 realizaba a la postre, utilizando el art. 10.2, una interpretación del art. $24 \mathrm{CE}$ - en materia de garantías frente a las condenas en ausencia- no incompatible con la Euroorden y con el Derecho de la Unión, una interpretación ahora compatible, distinta de la que parecía derivarse del texto del Auto de planteamiento de la mencionada prejudicial que dio lugar a la STJ.

Por otro lado, merece la pena recordar que el TJUE suele hacer valer el Derecho de la Unión Europea también ante aquella jurisprudencia constitucional que ha entendido o interpretado ya una disposición constitucional de manera contraria a ese Derecho. Recuérdese en este sentido, por ejemplo, la STJUE A. Cordero Alonso, en la que el Tribunal daba a entender la incompatibilidad de una jurisprudencia reiterada del TC español en materia de igualdad (en concreto sobre la regulación diferenciada del régimen indemnizatorio del FOGASA en una situación de insolvencia del empresario) con el Derecho de la Unión (STJUE 2006, par. 41); o la Sentencia al asunto Landtová, en la que se hace ver la contraposición de una jurisprudencia del TC checo (en relación con un asunto sobre el régimen de pensiones de jubilación) con el principio de no discriminación por razón de la nacionalidad (STJUE 2011). Más recientemente, como hemos tenido ocasión de señalar con antelación, el TJ ha recalcado en su Sentencia Asociaţia 'Forumul Judecătorilor Din România' que el principio de primacía "se opone a una regulación de rango constitucional de un Estado miembro que, según la interpretación de su tribunal constitucional", lleva a una interpretación contraria al Derecho de la Unión (cit., par. 252).

Como venimos diciendo, la constatación de que una determinada interpretación constitucional resulta incompatible con el DUE no implica necesariamente que haya que reformar o remover la disposición constitucional que genera esa interpretación contrapuesta. La situación puede corregirse, como se ha señalado, interpretando esa disposición, en la medida que sea posible, de manera conforme o no opuesta al Derecho de la Unión.

50 La STJUE Consob (2021) podría ser otro ejemplo en este sentido, contando también este caso, como recuerda el profesor Alonso García (2021a: 14 y ss.), con la ayuda de la lectura sugerida o guiada por la Corte Costituzionale en la cuestión prejudicial planteada en el asunto (lectura de la CDFUE en cuanto al Derecho Fundamental en juego - derecho de toda persona a no declarar en su propia contra en el marco de procedimientos administrativos encaminados a la imposición de sanciones de carácter 


\section{(B) La vía de la reforma formal de la Constitución}

De no ser posible la solución de la interpretación constitucional conforme, el mecanismo más plausible para solucionar el conflicto entre Constitución y Derecho de la Unión es, a tenor también de la práctica existente, el de la reforma formal de la disposición constitucional conflictiva, la que encierra la norma o interpretación constitucional opuesta al Derecho de la Unión.

La reforma constitucional puede ser un mecanismo para soslayar un conflicto entre la norma constitucional y el DUE que aparece como evidente o inexorable. Pensemos, por ejemplo, en cómo el reconocimiento al ciudadano europeo en el Tratado comunitario del derecho de sufragio activo y pasivo en las elecciones municipales y al Parlamento Europeo (arts. 20.2 y 22 TFUE, antiguos 17.2 y 19 TCE) obligó a reformar normas constitucionales que se veía que iban a chocar ineludiblemente con el mismo (por ejemplo: el art. 119 Constitución lituana o, sin ir más lejos, el 13.2 de la Constitución española) ${ }^{51}$. La reforma constitucional puede también servir para salvar un conflicto una vez que se haya contrastado jurisdiccionalmente su existencia, sea vía jurisdicción nacional o del TJUE. Este fue el caso de la ya señalada Declaración 1/1992 de TC español con relación al artículo que se acaba de mencionar. Es posible también traer a colación al respecto, por ejemplo, los casos de reforma constitucional que han tenido lugar en relación con la Euroorden u Orden Europea de Detención y Entrega creada por Decisión Marco de $2002^{52}$ (que, como es sabido, consiste, en un procedimiento judicial simplificado y transfronterizo activado por un Estado miembro de la Unión con vistas a la detención y entrega de una persona por otro Estado miembro, a efectos de enjuiciamiento o de ejecución de una pena; procedimiento que viene a sustituir en los Estados miembros al tradicional sistema de extradición, introduciendo cambios significativos, por ej. respecto a la prohibición de entrega de los propios nacionales). Esta normativa europea ha obligado a modificar

\footnotetext{
sustancialmente punitivo- a la luz de la jurisprudencia del TEDH y de las tradiciones constitucionales comunes).

$51 \mathrm{O}$ pensemos en cómo tuvieron que ser reformadas determinadas cláusulas constitucionales económicas de algunos Estados, dispuestos a ingresar en la UE, que reservaban a los nacionales del Estado la propiedad de determinados bienes (tierras, aguas interiores, adquisición de inmuebles, etc.), lo cual entraba en conflicto con el principio de no discriminación por razón de la nacionalidad en relación con las libertades fundamentales del mercado (libre circulación de mercancías, servicios, etc.). En esta línea, Eslovenia tuvo que reformar el art. 68 de su Constitución por dos veces (reformas de 1997 y 2003) con el objeto de que también se reconociera a los extranjeros el derecho a adquirir bienes inmuebles. Lo mismo sucedió con la reforma constitucional en 2003 del art. 47 de la Constitución de Lituania, que establecía que "[1]a tierra, las aguas interiores, los bosques y los parques solo podrán pertenecer en propiedad a los ciudadanos de Lituania y el Estado lituano [...]".

52 Decisión Marco del Consejo relativa a la orden europea de detención y entrega entre Estados miembros (2002).
} 
las Constituciones de algunos países como, por ejemplo, Polonia, Alemania, Chipre o Eslovenia, por cuanto, expresado ahora de forma resumida, dichas Constituciones prohibían la extradición de los nacionales de sus países, lo que vino a constatarse que chocaba con la Decisión Marco sobre la Euroorden ${ }^{53}$. Cabe recordar, asimismo, por poner otro ejemplo, el derivado de la Sentencia Tanja Kreil del Tribunal de Justicia (2000), a raíz del cual hubo que modificar el art. 12a de la Ley Fundamental de la República Federal de Alemania, por ser incompatible con la normativa europea relativa al principio de igualdad de trato entre hombres y mujeres en el acceso al empleo, ya que excluía a las mujeres de los empleos militares que implicasen el uso de $\operatorname{armas}^{54}$.

53 Repárese, por ejemplo, en la Sentencia del Tribunal Constitucional polaco de 27 de abril de 2005, un pronunciamiento relativo a la ley nacional de aplicación de la decisión marco sobre la Orden de Detención Europea, en la que se declara la incompatibilidad del art. 607 del Código Procesal Penal (modificado por una Ley de 2004) con el art. 55(1) de la Constitución, que prohibía la extradición de ciudadanos polacos, "en la medida en que permite la entrega de un ciudadano polaco a otro Estado miembro de la Unión Europea sobre la base de la Orden Europea de Detención”. La Sentencia señalará, además, a las autoridades nacionales la conveniencia de modificar la Constitución para salvar la incompatibilidad, otorgando para dicho cambio un plazo máximo de dieciocho meses (de acuerdo con el art. 190.3 de la Constitución, que permite diferir los efectos de una declaración de inconstitucionalidad por ese periodo). La reforma constitucional del art. 55 fue aprobada el 7 de noviembre de 2006, admitiéndose la extradición de ciudadanos polacos, aunque sometida a la doble condición de que lo sea por hechos cometidos fuera de Polonia y que estén tipificados como delitos en el Derecho polaco. Algo similar sucedió en Chipre, con la reforma constitucional que entró en vigor el 28 de julio de 2006, una vez que el Tribunal Supremo confirmó que la entrega de ciudadanos chipriotas era inconstitucional [Decisión del Tribunal Supremo (CY) de 7 de noviembre de 2005]. Igualmente, Eslovenia se vio obligada a revisar el art. 47 de la Constitución, el cual prohibía la extradición de ciudadanos eslovenos, y fue enmendado en 2003 para poder cumplir con las obligaciones europeas al respecto. Por su parte, Alemania enmendó también su Constitución, en concreto el art. 16 que prohibía de forma inequívoca la extradición del ciudadano alemán de cara a compatibilizar la misma con la que iba a ser la Decisión Marco sobre la Orden de Detención Europea que venimos señalando. Tras la reforma, que entró en vigor el 30 de noviembre de 2000 [Enmienda $\mathrm{n}^{\circ} .47$ a la Ley fundamental, de 29 de noviembre del año 2000 (BGBl. 2000 I: 1633)], el segundo apartado del mencionado artículo dispone, atenuando la prohibición de extradición, que "ningún alemán podrá ser extraditado al extranjero. Por ley se podrá adoptar una regulación divergente para extradiciones a un Estado miembro de la Unión Europea o a un Tribunal internacional, siempre que se respeten los principios del Estado de Derecho". Sobre el tema, entre otros muchos: Iglesias Sánchez (2010), quien llegará a la conclusión de que, "en la práctica, la jurisprudencia de los Tribunales Supremos y Constitucionales relativa a la euroorden constituye un buen ejemplo del reconocimiento de la primacía del derecho de la Unión. Si bien no se ha procedido en las sentencias comentadas a la inaplicación de las disposiciones afectadas de la Constitución nacional para hacer prevaler una norma de transposición que asegurase el cumplimiento de la Decisión marco, la primacía del Derecho de la Unión ha sido asegurada a través del mandato de reforma constitucional para permitir que fuera posible la entrega de los propios nacionales" (p. 186).

54 En el caso se constató que la normativa comunitaria relativa a la aplicación del principio de igualdad de trato entre hombres y mujeres en lo que se refiere al acceso 
Finalmente, debe contemplarse que existe también la posibilidad de salvar el conflicto entre Constitución nacional y Derecho de la Unión no ya con la reforma de la disposición constitucional conflictiva sino, incluso, mediante la modificación o revisión formal del texto de la disposición europea contradicha. A nadie se le escapa que esta es una solución más improbable, máxime cuando de lo que se trate sea de modificar el Derecho originario, si bien, todo sea dicho, esto ya se ha producido en una ocasión; en concreto en Maastricht (1992), cuando se introdujo un cambio en el propio Tratado comunitario, adoptando el Protocolo ( $\left.n^{\circ} 35\right)$ sobre el art. 40.3.3 de la Constitución Irlandesa con el fin de evitar un eventual conflicto futuro con la misma ${ }^{55}$.

al empleo (Directiva 76/207/CEE relativa a la aplicación del principio de igualdad de trato entre hombres y mujeres en lo que se refiere al acceso al empleo, a la formación y a la promoción profesionales, y a las condiciones de trabajo), se oponía a la aplicación de disposiciones nacionales, como las del Derecho alemán, incluido el mencionado artículo de la Constitución, que, de manera general, excluían a las mujeres de los empleos militares que implicasen el uso de armas autorizando su acceso solo a las unidades sanitarias y a las formaciones de música militar. La solución vino de la mano de la reforma constitucional, con fecha de 20 de diciembre de 2000, del art. 12a IV in fine de la Ley Fundamental, sustituyéndose la última frase de tal precepto [“[...] En ningún caso podrán prestar un servicio con armas"] por otra que establece ahora que "En ningún caso podrán ser [las mujeres] obligadas a prestar servicio con las armas".

Ahí está también el caso Michaniki AE surgido a raíz de una prejudicial planteada por el Consejo de Estado Griego acerca de la interpretación de una Directiva sobre procedimientos de adjudicación de contratos públicos de obras (Directiva 93/37/ $\mathrm{CEE}$ ), en la que el TJ, además de precisar el contenido de esta Directiva, tiene ocasión de hacer constar que la misma se opone a una norma constitucional griega (por cierto, introducida vía reforma constitucional) por establecer esta una incompatibilidad absoluta - hasta el punto de vulnerar el principio de proporcionalidad - entre el sector de los contratos públicos y el de los medios de comunicación (STJUE 2008).

55 Protocolo según el cual "ninguna disposición de los Tratados afectará a la aplicación en Irlanda de ese art. 40.3.3 de la Constitución irlandesa". Es una modificación del Derecho originario de la Unión que se introdujo con objeto de soslayar el riesgo de una posible incompatibilidad entre ese artículo constitucional y la libre prestación de servicios de la Unión. Se trata, por cierto, de un artículo constitucional irlandés que fue, a su vez, reformado también en noviembre de 1992 (Decimocuarta Enmienda constitucional) para conciliar la Constitución con el Derecho de la UE, señalando que dicho artículo - con el que no era posible adoptar una legislación que permitiera la interrupción voluntaria del embarazo más allá de circunstancias excepcionales- no pone límites a la libertad de movimientos de Estado a Estado ni tampoco a la libertad para conseguir o hacer disponible información relativa a servicios lícitamente disponibles en otro Estado (una reforma constitucional dirigida a "eliminar" las dudas que se podían derivar del caso de la STJUE Grogan, 1991). Cabe señalar que ese art. 40.3.3 fue introducido en 1983 mediante la conocida como Eighth Amendment de la Constitución —aprobada en referéndum de septiembre del mismo año- en la que se disponía que "The State acknowledges the right to life of the unborn and, with due regard to the equal right to life of the mother, guarantees in its laws to respect, and, as far as practicable, by its laws to defend and vindicate that right", luego modificado, como se ha dicho, en 1992, y finalmente derogado en 2018, tras el referéndum celebrado el mismo año. 


\section{(C) Otras "salidas", última estación}

Más allá de la vía interpretativa ("interpretación constitucional conforme" al Derecho de la Unión e/o "interpretación flexible” de la primacía por parte del TJ) y de la vía de la modificación formal de la disposición (constitucional o europea) conflictiva, solo queda la persistencia en la confrontación y el incumplimiento o la "puerta" del art. 50 TUE, la retirada de la Unión. Y así lo recordará de forma muy gráfica el Abogado General E. Tanchev al valorar la ya mencionada declaración del Tribunal Constitucional Alemán en el asunto Weiss, cuando recuerda que:

"con arreglo a los Tratados, ningún órgano jurisdiccional nacional puede revocar una sentencia del Tribunal de Justicia, puesto que entonces el Derecho de la Unión no se aplicaría en condiciones de igualdad ni de manera efectiva en los 27 Estados miembros y se pondría en duda toda la base jurídica de la Unión. Si un tribunal constitucional nacional considera que un acto de la Unión o que un fallo del Tribunal de Justicia es contrario a su Constitución, no puede simplemente declarar que no es aplicable en su jurisdicción. Lo que puede hacer es intentar solucionar la situación obligando a su Gobierno a reformar la Constitución, tratar de cambiar la normativa de la Unión de que se trate a través del proceso político de la Unión o, en caso necesario, retirarse de la Unión ${ }^{56 " . ~}$

56 Conclusiones A.B. y otros (2020, par. 84, énfasis añadido), citando, al respecto: Kelemen, Eckhout, Fabbrini, Pech y Uitz (2020).

Es interesante recordar, en este sentido, cómo ya el TC español señalaba en la Declaración 1/2004 que "en el caso difícilmente concebible de que en la ulterior dinámica del Derecho de la Unión Europea llegase a resultar inconciliable este Derecho con la Constitución española, sin que los hipotéticos excesos del Derecho europeo respecto de la propia Constitución europea fueran remediados por los ordinarios cauces previstos en esta, en última instancia la conservación de la soberanía del pueblo español y de la supremacía de la Constitución que este se ha dado podrían llevar a este Tribunal a abordar los problemas que en tal caso se suscitaran, que desde la perspectiva actual se consideran inexistentes, a través de los procedimientos constitucionales pertinentes, ello aparte de que la salvaguarda de la referida soberanía siempre resulta a la postre asegurada por el art. I-60 del Tratado [antecedente del vigente art. 50 TUE, que regula la retirada de la UE], verdadero contrapunto de su art. I-6, y que permite definir en su real dimensión la primacía proclamada en este último, incapaz de sobreponerse al ejercicio de una renuncia, que queda reservada a la voluntad soberana, suprema, de los Estados miembros". 


\section{NUEVAS APORTACIONES SOBRE LOS MECANISMOS DE SALIDA A LA VULNERACIÓN DEL PRINCIPIO DE PRIMACÍA}

\subsection{En relación con la actuación de la jurisdicción constitucional nacional (o de "cómo barrer la propia casa")}

\section{(A) Con relación al mecanismo de la interpretación conforme}

Tal y como se desprende de una jurisprudencia reiterada del TJ, las autoridades de los Estados miembros, y particularmente, en el marco de sus competencias, las autoridades judiciales, están obligadas a interpretar el Derecho nacional, en la medida de lo posible, conforme al Derecho de la Unión ${ }^{57}$, en atención al principio de su efectividad ${ }^{58}$. Esta obligación comunitaria de interpretación conforme (consistent interpretation) alcanza hasta el punto de tener que tomar en consideración "todo el Derecho nacional", sea anterior o posterior a la norma europea, para apreciar en qué medida puede aquel ser objeto de una aplicación que no lleve a un resultado contrario al perseguido por el Derecho de la Unión ${ }^{59}$. Eso sí, siempre con el límite de no realizar una interpretación que conlleve un resultado contrario a la literalidad (contra legem) de ese Derecho nacional ${ }^{60}$, y sin descuidar que esa exigencia de interpretación conforme incluye también la obligación del órgano jurisdiccional nacional de "modificar, en caso necesario, su jurisprudencia reiterada si esta se basa en una interpretación del Derecho nacional incompatible con los objetivos del Derecho de la Unión" ${ }^{1}$.

57 STJUE Von Colson y Kamann (1984, par. 26). Véanse, asimismo, entre otras, las SSTJUE: Marleasing (1990), Inter-Environnement Wallonie (1997), Carbonari y otros (1999) o Pfeiffer y otros (2004).

58 "El principio de que el Derecho nacional debe interpretarse de conformidad con el Derecho de la Unión, en virtud del cual el órgano jurisdiccional nacional está obligado, en la mayor medida posible, a interpretar el Derecho nacional en conformidad con los requisitos del Derecho de la UE, es inherente al sistema de los Tratados, ya que permite al tribunal nacional, dentro de los límites de su competencia, garantizar la plena eficacia del Derecho de la UE cuando determina el litigio que tiene ante sí" [STJUE Asociația 'Forumul Judecătorilor Din România' (2021, par. 246), Poptawski (2019, par. 55)].

59 STJUE Pfeiffer y otros (cit., par. 115). La toma en consideración de "todo el Derecho nacional" haría una referencia a todas las normas del mismo, pero también a todos sus "métodos de interpretación" (ibid., par. 116).

${ }^{60}$ Por ejemplo: STJUE Sorge (2010, par. 52). Para un análisis en profundidad del mecanismo de la interpretación conforme, véanse, entre otros: Alonso García (2008), Bernardi (2015) o Cudero Blas (2019).

61 STJUE: Dansk Industri (2016, par. 33). Como recuerda el TJ, "por tanto, el tribunal remitente no puede, en el litigio principal, considerar válidamente que se en- 
Es discutible si la obligación jurisdiccional de interpretar el Derecho nacional conforme al Derecho de la Unión alcanza o no, en cuanto obligación establecida por el Derecho de la Unión, a la jurisdicción constitucional; al menos si, como es el caso del TC español, este tribunal no se concibe a sí mismo como juez de aplicación del Derecho de la Unión ${ }^{62}$. Otra cosa es que esa obligación de que también el Tribunal Constitucional realice su tarea interpretativa conforme al Derecho de la Unión sea una exigencia que se entienda fundamentada en la propia Constitución nacional, esto es, como una obligación constitucional (sea en atención a la cláusula constitucional de integración europea y/o a una cláusula de apertura constitucional al Derecho supraestatal de los Derechos Humanos, incluido el Derecho de los derechos fundamentales de la UE, a modo, por ejemplo, de lo recogido en el art. 10.2 $\mathrm{CE})^{63}$, sin perjuicio de que puedan pesar también las inconveniencias derivadas de no realizar la interpretación conforme. No es este el momento para profundizar en este sugerente y complicado tema, pero sí resulta importante resaltar la gran relevancia que tiene la existencia de una obligación que constriña, cualquiera que sea su fundamento último, a la jurisdicción constitucional a realizar una interpretación de la Constitución conforme al Derecho de la Unión (con el límite del contra constitutionem, esto es, sin que la interpretación pueda llevar a un resultado que sea contrario a la literalidad de la Constitución).

Ahora bien, tampoco puede olvidarse en este ámbito que, a la luz del principio de primacía, cuando no pueda interpretarse el Derecho nacional de conformidad con los requisitos del Derecho de la UE, el órgano jurisdiccional nacional encargado de aplicar el Derecho de la Unión en el caso debe negarse a aplicar cualquier disposición o resolución nacional contraria al Derecho de la Unión sin necesidad de solicitar o esperar a que la misma sea anulada o removida ${ }^{64}$. En este sentido, el Tribunal de Justicia viene adoptando deci-

cuentra imposibilitado para interpretar la norma nacional de que se trata de conformidad con el Derecho de la Unión, por el mero hecho de que, de forma reiterada, ha interpretado esa norma en un sentido que no es compatible con ese Derecho" (ibid., par. 34). Véanse, igualmente, las SSTJUE: Egenberger (2018, párs 72 y 73 ) e $I R / J Q$ (2018, párs 63-65).

62 Sobre las funciones desempeñadas por el TC en relación con el Derecho de la UE (promoción o impulso de la cooperación judicial y sus mecanismos en el espacio europeo; actuar como garante de la correcta utilización de la jurisdicción constitucional y su delimitación con la cuestión prejudicial europea; ser partícipe e interlocutor directo con el TJUE, en particular mediante la mencionada prejudicial), y la gradual incorporación por la jurisdicción constitucional del Derecho de la UE como parámetro de enjuiciamiento en el canon de constitucionalidad: Sarmiento (2021).

${ }^{63}$ Las actividades de interpretación de la Constitución nacional conforme al Derecho de la Unión que ha llevado a cabo el TC español, como, por ejemplo, las realizadas en las ya mencionadas Declaración 1/2004 o STC 26/2014 (véase supra apartado 4.A) habrían estado fundamentadas en la propia Constitución nacional y no habrían sido concebidas como una exigencia fundada en el Derecho de la Unión.

${ }^{64}$ Ahora, por todas: Sentencia Asociaţia 'Forumul Judecătorilor Din România' (2021, par. 247). 
siones en las que se da a entender que no se pueden admitir interpretaciones de la Constitución nacional realizadas por la jurisdicción constitucional que sean contrarias al Derecho de la Unión, siendo particularmente elocuente al respecto, como se ha podido destacar ya, la reciente y reiterada Sentencia TJ Asociaţia 'Forumul Judecătorilor Din România'65.

Por lo demás, debe tenerse en cuenta que el esfuerzo de seguir la vía de la interpretación conforme puede terminar propiciando que el conflicto se solucione mediante la actividad hermenéutica del propio Tribunal de Justicia, en concreto a través de una interpretación "flexible" del principio de primacía en el caso en cuestión (como en la STJUE Taricco II). Esta posición flexibilizadora de la primacía puede verse favorecida, claro está, por la colaboración previa de la jurisdicción constitucional a través del planteamiento de una cuestión prejudicial al TJ. El diálogo en la actividad y esfuerzo interpretativo puede ser particularmente útil en los casos de conflicto en los que está en juego la identidad constitucional.

Debemos recordar, en este sentido, cómo el Abogado General E. Tanchev reprochaba al Tribunal Constitucional alemán (en el caso A.B. y otros) el haberse apartado en el asunto Weiss de su propia línea jurisprudencial y del diálogo judicial, cuando resalta que "el BVerfG podría haber explicado lo que, a su juicio, era criticable en la jurisprudencia del Tribunal de Justicia y, a continuación, podría haber planteado una nueva petición de decisión prejudicial al Tribunal de Justicia". De hecho, recuerda el Abogado General, esa es la solución que debería haber adoptado el Tribunal de Karlsruhe si hubiera seguido su propia línea de jurisprudencia sobre este extremo, refiriéndose tanto a su propio concepto de diálogo judicial desarrollado en la sentencia de 6 de julio de 2010 en el asunto Honeywell 66, como al juego que dio, en este sentido, la ya mencionada cuestión prejudicial remitida por la Corte Constitucional en el affaire Taricco. Después de todo, insistía E. Tanchev, el diálogo judicial es un elemento de gran valor e inherente al funcionamiento del ordenamiento jurídico de la Unión ${ }^{67}$.

65 Par. 252. Una sentencia que, al igual que sucede con otras anteriores en esta línea - como, por ejemplo, la ya mencionada Krizan y otros-, trae causa de una cuestión prejudicial planteada por la jurisdicción ordinaria, precisamente, ante las dudas que le genera a un órgano jurisdiccional nacional una resolución previa de la jurisdicción constitucional en cuanto a su corrección en términos de Derecho de la UE. Respecto al fenómeno del control (judicial) de europeidad de las resoluciones jurisdiccionales (que abarca también las resoluciones de la jurisdicción constitucional) me permito citar mi previo trabajo: Ugartemendia Eceizabarrena (2016).

66 BVerfG 2 (2010). Véase, al respecto: Paris (2018: 217 y ss.).

${ }^{67}$ Par. 82 de las Conclusiones. Analizando la capacidad de diálogo táctico con el Tribunal de Justicia de la UE como uno de los rasgos que, a diferencia de otros Tribunales, caracterizan a la Corte Costituzionale italiana: Von Bogdadndy y Paris (2020: 9 y ss.). 


\section{(B) Con relación al mecanismo de la reforma constitucional (la oportunidad de implicar a la jurisdicción constitucional)}

Constatada la colisión normativa entre Constitución y Derecho de la Unión, y no siendo posible salvarla mediante la vía interpretativa, parece claro que la solución más viable al problema pasa, como se ha descrito ya, por la reforma de la disposición constitucional nacional que resulta incompatible con el Derecho de la Unión. En cualquier caso, la jurisdicción constitucional puede, también aquí, desempeñar cierta actividad que repercuta de alguna manera en el arreglo del problema.

En efecto, la jurisdicción constitucional puede contribuir algo a ese remedio indicando, cuando tenga ocasión, la oportunidad de que se realice una reforma constitucional para solucionar el problema, ante la imposibilidad de que pueda realizarse una interpretación de la Constitución conforme al Derecho de la Unión. Esta es una posibilidad que no carece de antecedentes. Es el caso, por ejemplo, del Tribunal Constitucional polaco, cuando apunta a las autoridades del país la conveniencia de modificar el art. 55 de la Constitución para salvar el conflicto con la normativa europea sobre la euroorden de detención y entrega ${ }^{68}$, o el del Tribunal Supremo de Chipre en el ámbito de la misma normativa europea ${ }^{69}$. Y ese es el caso que se dio, por poner un ejemplo cercano, en el proceso que condujo a la primera reforma constitucional de la Constitución Española, cuando el Tribunal Constitucional, una vez constatada la contradicción entre el Tratado comunitario (art. 8 B, apartado 1, TCE, según quedaría redactado por el Tratado de la Unión Europea) y la Constitución nacional (art. 13.2) "irreductible por la vía de la interpretación", afirma que:

"la única vía existente en Derecho para superar tal antinomia, y para ratificar o firmar aquel tratado, es, así, la que ha previsto la Constitución en su art. 95.1: la previa revisión de la Norma fundamental en la parte de la misma que impone hoy la conclusión de esta declaración. Dicha reforma constitucional habrá de remover el obstáculo contenido en el art. 13.2, que impide extender a los no nacionales el derecho al sufragio pasivo en las elecciones municipales (DTC 1/92, FJ 6)"70.

68 Sentencia del Tribunal Constitucional polaco de 27 de abril de 2005. La reforma constitucional fue luego aprobada el 7 de noviembre de 2006 (vid. supra punto 4.B).

69 Con la reforma constitucional que entró en vigor el 28 de junio de 2006, una vez que el Tribunal Supremo confirmó que la entrega de ciudadanos chipriotas en el contexto de la mencionada euroorden era inconstitucional [Decisión del Tribunal Supremo (2005)].

70 (Énfasis añadido), en el marco del control previo de constitucionalidad ex arts. 95.2 CE y 78 LOTC. Por otro lado, es posible también traer aquí a colación la actitud, ya descrita, de la jurisdicción constitucional maltesa en el asunto de la STJUE Repubblika/II-Prim Ministru (2021) cuando, excluida la vía de la interpretación conforme, es ella misma la que plantea una remisión prejudicial al TJ para que sea este quien controle la corrección, según los estándares o parámetros del Derecho de la Unión Europea, de determinadas disposiciones constitucionales incorporadas vía reforma consti- 
Pero el señalamiento de la oportunidad o necesidad de la reforma no es la única forma de ayuda que puede desarrollar aquí el Tribunal Constitucional. Todavía es factible apuntar la posibilidad de otra actuación para la solución de las contraposiciones entre Derecho de la Unión y disposición constitucional, aunque sea más compleja de articular y solo sirva para el caso del control de las disposiciones constitucionales de reforma constitucional que eventualmente puedan entrar en colisión con el Derecho de la Unión. Se trata de la idea, sugerida en un trabajo del profesor Pedro Cruz Villalón, consistente en articular un "control previo" de la reforma de la Constitución nacional que permitiera al Tribunal Constitucional pronunciarse sobre la misma antes de que fuera aprobada. Ahora bien, como puntualiza el mismo profesor, "el solo enunciado de esta pretensión pone de manifiesto la dificultad de esta variante de control previo, en particular en un contexto como el español que no reconoce otro Derecho aplicable a la reforma que no sea el procedimental, y aun esté carente de un proceso de control", a diferencia, sigue recordando el autor, de lo que acontece con las Constituciones con cláusulas de intangibilidad material, como es el caso de la Ley Fundamental de Alemania, en cuyo contexto el control material de la reforma constitucional se encuentra perfectamente asimilado.

Y es que los Tribunales Constitucionales nacionales no son hoy por hoy 'intérpretes supremos' de otra Constitución que no sea la nacional. Formalmente, en el caso español, podría ser suficiente con 'darle la vuelta' al art. $95 \mathrm{CE}$, es decir, prever la posibilidad de que el Tribunal Constitucional se pronuncie de forma previa sobre los proyectos de reforma cuya europeidad sea dudosa. Desde un punto de vista material, sin embargo, no se oculta la trascendencia de una previsión constitucional de este tipo (2004: 77-78).

En cualquier caso, debe tenerse en cuenta que ese pronunciamiento previo del Tribunal Constitucional podría, lógicamente, contar con el auxilio de la remisión prejudicial al Tribunal de Luxemburgo para determinar la compatibilidad del proyecto de reforma con el Derecho de la Unión ${ }^{71}$.

Llegados aquí es posible señalar que toda la dinámica de adecuación de la Constitución nacional al Derecho de la Unión derivada del imperio del principio de primacía, particularmente la de activar procedimientos de reforma constitucional para salvar el conflicto con el Derecho de la Unión, podría llevar a pensar que el texto constitucional queda a merced del ordenamiento jurídico de la UE. Y no solo del Derecho originario, sino también, incluso, del

tucional, disposiciones que a la sazón eran parte de la vigente Constitución nacional. Para más detalles del caso véase supra el punto 2 in fine de este trabajo. Es evidente que esta forma de proceder de la jurisdicción constitucional maltesa, que parece difícil de concebir en otros países, aunque no está sugiriendo la reforma constitucional, sí estaría, sin embargo, conduciendo a la misma en el caso de que la resolución del TJ a la prejudicial planteada indicara que el Derecho de la Unión se opone a la disposición constitucional en cuestión, conectando, de esta forma, cuestión prejudicial europea y reforma constitucional nacional (¿prejudicial prorreforma?).

${ }^{71} \mathrm{Al}$ respecto, también, Ferreres (2013: 69). 
Derecho derivado, el cual, téngase en cuenta, puede ser aprobado (allá donde, como ocurre en la mayoría de los muchos ámbitos de poder atribuidos a la Unión, no se exige unanimidad en el Consejo para su aprobación) en contra de la voluntad del Estado cuya Constitución puede colisionar con el DUE. Resulta evidente el hecho de que el poder de integración europeo y el Derecho de la Unión condicionan al poder constituyente del Estado, limitándolo. Y ello porque nos encontramos ante un constituyente empujado a reformar o a no incorporar disposiciones constitucionales contrarias al Derecho de la Unión (aunque sean posteriores). En este sentido, puede decirse que el Poder Constituyente de un Estado miembro de la Unión Europea es ya, utilizando una expresión avanzada por el profesor Pedro Cruz Villalón, un “constituyente limitado" por el Derecho de la Unión ${ }^{72}$.

Ahora bien, tampoco hay que perder de vista, particularmente cuando se habla de la reforma constitucional en el contexto del principio de primacía del Derecho de la Unión, que, como bien precisó el Tribunal Constitucional español en la Declaración 1/1992, el poder de integración europea no sustituye ni puede disponer del poder de reforma constitucional ${ }^{73}$. El Derecho de la Unión Europea podrá regir y primar sobre el Derecho nacional, incluso sobre la Constitución (con los límites señalados), pero no puede reemplazar o desplazar al poder de reforma constitucional nacional. La modificación del texto constitucional provocada por el Derecho de la Unión para salvar el conflicto con el mismo necesita del poder de reforma constitucional para poder concretarse. Sin este poder el DUE no puede terminar de regir y primar sobre la disposición constitucional contraria al mismo (no puede remover la disposición nacional incompatible). "Los enunciados de la Constitución no pueden ser contradichos sino mediante su reforma expresa (por los cauces del Título $\mathrm{X})$ " 74 . Y en este sentido, aunque el DUE empuje a activar procedimientos de reforma o ejerza también como límite del poder mismo de reforma constitucional, no hay que olvidar que este poder de reforma actúa, a su vez, como un límite del principio de primacía del Derecho de la Unión, fungiendo a modo de un mecanismo de garantía de la supremacía de la Constitución nacional ${ }^{75}$.

72 2004: 66 y 77.

73 "En virtud del art. 93 las Cortes Generales pueden, en suma, ceder o atribuir el ejercicio de «competencias derivadas de la Constitución», no disponer de la Constitución misma, contrariando, o permitiendo contrariar, sus determinaciones, pues, ni el poder de revisión constitucional es una "competencia» cuyo ejercicio fuera susceptible de cesión, ni la propia Constitución admite ser reformada por otro cauce que no sea el de su Título X, esto es, a través de los procedimientos y con las garantías allí establecidos y mediante la modificación expresa de su propio texto. Esta es la conclusión que impone el dictado del art. 95.1 [...]” (Declaración 1/1992 del TC, FJ 4).

74 FJ 4 de la DTC 1/1992.

75 Para recordar cómo concilia el Tribunal Constitucional español la "supremacía" de la Constitución nacional con la "primacía" del Derecho de la Unión, véase la Declaración 1/2004, de 13 de diciembre [relativa al Requerimiento formulado por el Gobierno de la Nación acerca de la constitucionalidad de los arts. I-6 (principio de primacía del Derecho de la Unión), II.111 y II-112 (relativos al ámbito de aplicación y al alcance 
Siguiendo un cierto paralelismo con la idea del art. 95.1 CE, podría decirse que la existencia de una disposición de Derecho de la UE que contenga estipulaciones contrarias a la Constitución estaría requiriendo la previa revisión constitucional ${ }^{76}$. Esa reforma permite así, no solo salvar la primacía del Derecho de la Unión, sino también preservar la supremacía constitucional ${ }^{77}$.

\subsection{En relación con la jurisdicción del TJUE (o sobre "cómo escuchar al otro")}

Con la jurisdicción constitucional sucede algo similar a lo que acontece con la reforma constitucional. Se trata de otro mecanismo para garantizar la supremacía de la Constitución que se ve también condicionado por el Derecho de la Unión, sea porque este incide directamente sobre los poderes cuya actividad debe controlar con parámetros constitucionales, sea por la necesidad, ya descrita, de realizar la interpretación de la Constitución nacional de manera conforme al DUE. Pero ese condicionamiento por parte del Derecho de la Unión (y del TJUE) no puede llegar a implicar ni sumisión ni posibilidad de disponer del poder de jurisdicción constitucional, del mismo modo que tampoco conllevaba disponer del poder de reforma constitucional. La jurisdicción constitucional no puede renunciar a actuar de garante de la supremacía de la Constitución, aunque sea haciendo equilibrios, incluso cabriolas, en relación con el respeto de la primacía del Derecho de la Unión.

De ahí que gestionar, en caso de conflicto, la operación de hacer valer la primacía del DUE sobre la constitución nacional consista en una operación de delicada cirugía o tratamiento constitucional, una actividad que exige, en lógica y buena correspondencia, tratar de mantener un equilibrio con res-

e interpretación de los Derechos Fundamentales de la Unión Europea) del Tratado por el que se establece una Constitución para Europa firmado en Roma el 29 de octubre de 2004], FJ 4. Para un análisis detenido de las cuestiones derivadas, entre otros: López Castillo, Saiz Arnaiz y Ferreres Comella (2005), Rodríguez Iglesias (2005).

76 Claro está, de no ser posible salvar la colisión mediante una interpretación constitucional conforme y salvo que se trate de estipulaciones contrarias al propio Derecho de la Unión (incluidos los mencionados arts. 4 y 5 TUE, donde, entre otras cosas, se prohíbe la actuación europea en ámbitos competenciales no atribuidos o vulnerando la identidad constitucional).

77 Del mismo modo que, como recuerda el profesor Pablo Pérez Tremps, esa previsión constitucional de reforma del art. 95.1 CE ("La celebración de un tratado internacional que contenga estipulaciones contrarias a la Constitución exigirá la previa revisión constitucional") permite preservar la supremacía de la Constitución ante el tratado que se le opone, imposibilitando que exista contradicción entre ambas normas; disponiéndose después, además, en el art. 95.2 CE, un mecanismo de consulta o control preventivo de constitucionalidad ante el Tribunal Constitucional sobre la existencia o no de dicha contraposición (en López Guerra et al., Derecho Constitucional, 2018: 107). 
pecto a la supremacía normativa que esgrime cada Constitución nacional. Y esto vale en cuanto a la jurisdicción constitucional nacional, pero también, especialmente, en relación con la jurisdicción del TJUE.

En este sentido, merece la pena mencionar, siquiera de forma muy breve, los intentos de búsqueda de soluciones que permitan sostener ese equilibrio, teniendo en cuenta, precisamente, a la propia jurisdicción constitucional nacional a la hora de tomar, por parte del TJUE, la decisión que tenga que solventar la eventual contraposición entre disposición constitucional nacional y Derecho de la Unión (salvando la primacía de esta). En lo que sigue nos centraremos, de forma sumaria, en los más interesantes de esos intentos de contar con la correspondiente jurisdicción constitucional, ciñéndonos a las propuestas posteriores a la Sentencia Weiss del Tribunal Constitucional alemán, momento a partir del cual empiezan a proliferar.

(a) Comenzaremos refiriéndonos a la propuesta de los profesores Joseph H.H. Weiler y Daniel Sarmiento de crear una Sala Mixta en el Tribunal de Justicia de la Unión Europea para resolver, en última instancia, los conflictos de competencia entre la UE y los Estados miembros. El punto de partida de la propuesta reside en la idea que forjan las siguientes cuestiones: ¿Qué debe hacer un tribunal constitucional nacional, que tiene la responsabilidad última de garantizar el Estado de Derecho, los derechos humanos y los principios de la democracia dentro de su jurisdicción, si se enfrenta a una medida de la Unión que, en su opinión, viola dichos valores? ¿Y qué debe hacer ese tribunal cuando una sentencia del Tribunal de Justicia, garante de todos esos valores en el ámbito de las competencias de la Unión, legitima esa medida de la Unión de un modo que el tribunal nacional considera inadecuado? Y, todavía de forma incluso más intensa, ¿cómo debe actuar esa jurisdicción si de lo que se trata es de la línea que delimita las competencias respectivas de la Unión y de sus Estados miembros, teniendo en cuenta que aquella obtiene sus poderes y competencias por delegación de estos? Aunque procesalmente el Tribunal de Justicia es el único órgano jurisdiccional facultado para pronunciarse en materia de Derecho de la Unión Europea sobre estas cuestiones, surge, sin embargo, la pregunta de si no corresponde, al menos en parte, al Derecho nacional definir lo que puede delegarse constitucionalmente.

El fantasma de la resolución Weiss del Tribunal de Karlsruhe se apoyaría, de alguna manera, en los problemas que se derivan de estas cuestiones. Para evitar que puedan reproducirse resoluciones de ese tipo, y observando que el statu quo post-Weiss no es viable a largo plazo, los autores mencionados proponen el establecimiento de una nueva jurisdicción de apelación dentro del Tribunal de Justicia, limitada estrictamente a los casos de ese tipo, aquellos en los que se cuestiona la delimitación de la línea jurisdiccional entre los Estados miembros y su Unión.

Se trataría de una Sala compuesta por miembros titulares del Tribunal de Justicia junto con miembros titulares de los tribunales constitucionales o equivalentes de los Estados miembros, que solo se pronunciaría sobre el 
reparto de competencias entre la UE y sus Estados miembros, siendo competente para declarar la nulidad de un acto de la UE — revocando una decisión anterior del Tribunal de Justicia que lo valide- que supusiera una violación grave del principio de atribución (el criterio de revisión se limitará a los casos de "violación grave"). El acceso a dicha Sala estaría en manos bien de los Estados miembros (Gobierno o Parlamento nacional) e instituciones de la Unión Europea (en estos casos a través de una acción directa), o bien del Tribunal Constitucional o Supremo de un Estado miembro (mediante remisión preliminar).

La concreción de la propuesta señalada exigiría, en todo caso, una revisión de los Tratados ${ }^{78}$.

(b) La segunda propuesta que interesa destacar consiste en establecer una vía prejudicial a la inversa ("reverse" preliminary ruling procedure), propuesta realizada por los presidentes de los Tribunales Constitucionales de Austria (Christoph Grabenwarter), Eslovenia (Rajko Knez), Letonia (Ineta Ziemele, Jueza del TJ desde octubre de 2020) y por el juez del Tribunal Constitucional Federal alemán Peter M. Huber, a la sazón uno de los autores de la Sentencia Weiss del BVerfG 79.

El fundamento de esta propuesta, tal y como se resume al inicio del artículo, parte de la idea de que los tribunales constitucionales desempeñan un papel primordial dentro del espacio judicial europeo y forman una rama específica de la red judicial europea, que incluye el Tribunal de Justicia de la Unión Europea y el Tribunal Europeo de Derechos Humanos. Tanto aquellos tribunales como el TJUE no solo tienen la tarea común de hacer cumplir la legislación de la $\mathrm{UE}^{80}$, sino también de preservar sus límites (en primer lugar, el principio de atribución y las identidades constitucionales de los Estados miembros), tareas que deben desarrollarse de forma cooperativa y dialógica.

Mientras que los tribunales nacionales (constitucionales) están obligados a respetar la autoridad del TJUE para decidir en última instancia sobre la interpretación de la legislación de la UE, es obligación del TJUE tomar sus remisiones con seriedad y abordar en profundidad las preocupaciones planteadas. A los tribunales constitucionales de los Estados miembros se les asigna la responsabilidad constitucional de acompañar el proceso de integración europea a fin de garantizar que los derechos soberanos solo se transfieran de conformidad con las disposiciones respectivas, así como que el ejercicio de las competencias respete los límites establecidos en los Tratados y no interfiera con las identidades

78 Sobre la propuesta y sus detalles, Weiler y Sarmiento (2020, 1 jun.); sobre los comentarios y críticas recibidos, así como las respuestas razonadas a los mismos por parte de los autores: (2020, 6 jul.). Acerca de la idea de un Tribunal europeo de conflictos (Tribunal Constitucional de la Unión Europea) integrado por magistrados de los Tribunales Constitucionales (o equivalentes) de los Estados miembros y del Tribunal de Justicia, véase: Requejo (2021: 38 y ss.).

79 Grabenwarter, Huber, Knez y Ziemele (2021).

80 Ibidem:49 y ss. 
constitucionales de los Estados miembros (Grabenwarter, Huber, Knez y Ziemele, 2021: 43 y 51 y ss.).

En este sentido, se entiende que la red de tribunales constitucionales puede realizar una cooperación decisiva con el TJUE siempre que sea asumida como una "cooperación entre iguales" ${ }^{81}$, siendo necesario para ello, además de intensificar los esfuerzos conjuntos, evaluar las posibilidades de mejorar la participación de los tribunales constitucionales, en particular mediante el establecimiento de un procedimiento prejudicial inverso.

Dado que el TJUE no puede decidir sobre el contenido de la respectiva identidad constitucional por sí mismo —el art. 4, apartado 2 TUE es una disposición del Derecho de la UE, pero se remite en esencia a las especificidades del derecho constitucional nacional- debe hacer un esfuerzo serio para averiguar el contenido de las disposiciones nacionales respectivas (ibidem: 58).

Y en esta línea, siempre que esté en juego una injerencia en la identidad nacional de un Estado miembro, el Tribunal de Justicia no debería ignorarlo, sino que estaría obligado a aclarar tales cuestiones, atendiendo a las aportaciones que puedan realizar los tribunales constitucionales nacionales, forjando un verdadero diálogo, no unidireccional, sino necesariamente bidireccional. En este sentido, lo ideal sería que ese diálogo se llevara a cabo mediante una remisión prejudicial "por parte del TJUE al órgano jurisdiccional nacional competente para dictar una resolución vinculante [binding decision] sobre la interpretación de la Constitución”. Los autores entienden que, entre los posibles métodos y modalidades de "participación de los tribunales constitucionales nacionales en la determinación de la identidad constitucional nacional" que puedan existir, este de la prejudicialidad inversa sería uno de ellos. Una modalidad que podría articularse modificando el TFUE e introduciendo dicho procedimiento prejudicial en un art. 267 bis del TFUE que obligara al TJUE a someter al tribunal constitucional (o supremo) correspondiente los asuntos que pudieran afectar a la identidad nacional de los Estados miembros, tal como se establece en el art. 4, apartado 2, del TUE ${ }^{82}$.

(c) Como acaba de observarse, las dos modalidades señaladas de participación de los tribunales constitucionales - o, en su caso, supremos- de los Estados miembros en la resolución de los conflictos del Derecho de la Unión con la Constitución nacional con ser muy interesantes, presentan, sin embargo, una gran limitación práctica en la medida que exigen la reforma de los Tratados, con las dificultades que ello comporta para que puedan ser llevadas a la práctica.

Por ello, y al menos mientras no se logre salvar esas dificultades, habría que valorar aquellas modalidades de participación de los tribunales constitucionales en la actividad el TJ que, sin perjuicio de su modestia, sean, además de útiles, más sencillas de articular. Así, son dignas de consideración otras

\footnotetext{
81 Ibid.: 57 y ss.

82 Ibid.: 59-60.
} 
ideas, como la señalada por los mismos autores que realizan la propuesta anterior, en el sentido de que por lo menos, los tribunales constitucionales deberían "ser invitados a actuar [ante el TJUE] como intervinientes en los casos relativos al constitucional nacional (del mismo modo que les es posible hacerlo a los Estados miembros y la Comisión de la UE en todos los casos)" 83 . En una línea similar, debe señalarse igualmente la idea, más precisa, apuntada por el profesor Ricardo Alonso García, cuando señala la posibilidad de:

"introducir ciertos ajustes técnicos en las reglas de procedimiento del Tribunal de Justicia, habilitando a los Tribunales Supremos y Constitucionales a personarse, a través de sus servicios jurídicos, en los asuntos pendientes en Luxemburgo en los que, a su parecer, fuere necesario aportar precisiones y criterios para encauzar, en sus debidos términos, el trabajo de los jueces europeos (2021, 11 may.: 14).

La propuesta parte de visualizar el fenómeno de la integración europea desde un constitucionalismo plural y multinivel, según el cual, las Constituciones nacionales serían "parte esencial y activa en la construcción dinámica y evolutiva de la, en sentido sustancial de la expresión, Constitución europea". Una visión que, de ser asumida, conllevaría necesariamente, a juicio del autor:

"la aceptación de los Tribunales Constitucionales como excepcionales interlocutores con el Tribunal de Justicia, por cuanto portavoces de los valores nacionales supremos; interlocución privilegiada que, por lo demás, debería también extenderse al marco de la vía prejudicial, en el que sus intervenciones tendrían que ser conceptualmente examinadas por el Tribunal de Justicia no en términos de subordinación, sino de diálogo, de par a par, con este último" (ibid.: 9-10).

\section{CONCLUSIÓN}

A lo largo de estas páginas hemos visto cómo, teniendo su arranque en la Sentencia Weiss del Tribunal Constitucional Federal alemán, se están produciendo recientemente una serie de resoluciones de diversos tribunales constitucionales que vienen a desafiar abiertamente el principio de primacía del Derecho de la Unión, haciendo valer para ello diversos límites derivados de la Constitución nacional. No se trata, como ocurría en el pasado, de meros avisos o escaramuzas de desavenencia, ni de clásicos ademanes o amagos de colisión. Son supuestos de beligerante oposición frontal a la primacía del Derecho de la Unión y de la jurisprudencia del TJ, que están transmitiendo, además, cierta sensación de conflicto a la hora de percibir las relaciones entre las jurisdicciones constitucionales y la jurisdicción del Tribunal de Justicia de la Unión.

Tras haber apuntado de manera sucinta las resoluciones conflictivas, así como los mecanismos para garantizar la primacía del Derecho de la Unión y

83 Ibid.: 60 . 
los límites que se suelen oponer a la misma, resulta patente que las salidas al conflicto generado por estos desafíos y la consecuente atmósfera de turbulencia pasan, de forma particular, por el uso del mecanismo de la interpretación de la Constitución nacional por parte de su supremo interprete de manera conforme al Derecho de la UE y, no siendo posible esta interpretación, acudiendo a la reforma formal de la disposición constitucional conflictiva en cuestión (sin descartar la improbable posibilidad de la modificación de la disposición europea contradicha). Un vistazo general a esta problemática y a la doctrina que se está generando en torno al principio de primacía pone en evidencia la necesidad de que, además de la implicación ya indicada de la jurisdicción constitucional (o incluso de una interpretación "flexible" del carácter absoluto de la primacía por parte del TJ), es necesario, asimismo, articular alguna fórmula que permita que esta jurisdicción constitucional sea escuchada en la resolución por parte del TJ de los conflictos relativos a la primacía del Derecho de la Unión que guardan relación con los límites que, a tenor de aquella jurisdicción, derivan de la Constitución nacional. Esa debida consideración o deferencia para con la jurisdicción constitucional terminará reforzando el principio de primacía del Derecho de la Unión, de la misma manera que el correcto uso de la interpretación constitucional conforme y de la reforma formal para salvar la primacía del Derecho de la Unión garantizan, contra lo que en apariencia pudiera parecer, la supremacía de la Constitución nacional.

\section{FUENTES CITADAS}

\section{A. Bibliografía}

Alonso García, R. (2008). La interpretación del Derecho de los Estados conforme al Derecho Comunitario: las exigencias y los límites de un nuevo criterio hermenéutico. Revista Española de Derecho Europeo, 28, 385-410.

Alonso García, R. (2021a). La puesta en práctica por la Corte Costituzionale de la protección multinivel del Derecho en la UE. ReDCE, 35. http://www.ugr.es/ redce/ REDCE35/articulos/04_ALONSO_GARCIA.htm

Alonso García, R. (2021b). Discurso del Dr. Ricardo Alonso García en el acto de su investidura como Dr. Honoris Causa por la Universidad Nacional Mayor de San Mar$\cos$ (Perú), Paraninfo de San Bernardo (UCM), 11 de mayo de 2021 (texto cedido por el autor)

Alonso García, R. (2021c, 25 jul.). Tiempos judiciales recios. La Razón.

Andrés Sáenz de Santa María, P. (2018). Sistema de Derecho Internacional Público (5. ${ }^{a}$ Ed.). Civitas/Thomson Reuters.

Bernardi, A. (Ed.) (2015), L'interpretazione conforme al Diritto dell'Unione Europea. Profili e limiti di un vincolo problemático, Jovene.

Cassia, P. (2021, 23 abr.). Le Frexit sécuritaire du Conseil d'Etat. En Blog del autor. https://blogs.mediapart.fr/paul-cassia

Cruz Villalón, P. (2004). El papel de los Tribunales Constitucionales nacionales en el futuro constitucional de la Unión. En P. Cruz Villalón, La Constitución inédita. Estudios ante la constitucionalización de Europa. Trotta. [publicado previamente en: C. Colneric, D. Edward y J.-P. Puissochet (Eds.).(2003). Une communauté de droit. 
Festschrift für Gil Carlos Rodríguez Iglesias (pp. 272-282). BWV/Berliner Wissenschafts Verlag]

Cudero Blas, J. (2019). El principio de interpretación conforme del Derecho de la Unión Europea: sus límites. En R. Alonso García y J.I. Ugartemendia Eceizabarrena (Dirs.), El juez nacional en su condición de juez europeo (pp. 89-106). IVAP.

Dimitrovs, A., y Kochenov, D. (2021, 15 jun.). Of Jupiters and Bulls: The Cooperation and Verification Mechanism as a Redundant Special Regime of the Rule of Law. EU Law Live, 61.

Ferreres, V. (2013). The Constitution of Spain. A Contextual Analysis. Hart Publishing.

Galetta, D.U., y Ziller, J. (2020). Les violations flagrantes et délibérées du droit de l'Union par l'arrêt «inintelligible» et «arbitraire» du Bundesverfassungsgericht dans l'affaire Weiss, RTDEur., 56, 855-887.

Grabenwarter, Ch., Huber, P.M., Knez, R., y Ziemele, I. (2021), The Role of the Constitutional Courts in the European Judicial Network. European Public Law, 27, 1, 43-62.

Iglesias Sánchez, S. (2010). La jurisprudencia constitucional comparada sobre la Orden europea de detención y entrega, y la naturaleza jurídica de los actos del Tercer Pilar. Revista de Derecho Comunitario Europeo, 35, 169-192.

Jacqué, J.J. (2010). Droit institutionnel de l'Union européenne (6. ${ }^{a}$ Ed.), Dalloz.

Kelemen, D., Eeckhout, P., Fabbrini, F., Pech, L., y Uitz, R. (2020, 26 may.). National Courts Cannot Override CJEU Judgments-A Joint Statement in Defense of the EU Legal Order. VerfBlog.

Kochenov, D., y Dimitrovs, A. (2021, 28 abr.). Solving the Copenhagen Dilemma: The Repubblika Decision of the European Court of Justice. VerfBlog. <https://verfassungsblog.de/solving-the copenhagen-dilemma

Lenaerts, K. (2020). L'égalité des États membres devant les traités: la dimensión transnationale du príncipe de primauté. Revue du droit de l'Union européenne, 4, 7-10.

Lenaerts, K. (2020, 8 oct.). No Member State is More Equal than Others. The Primacy of EU law and the Principle of the Equality of the Member States before the Treaties. Verfassungsblog. https://verfassungsblog.de/no-member-state-is-moreequal-than-others/

López Castillo, A. (2021). Del tránsito presidencial en la Sala 2. ${ }^{\text {a }}$ del TCFA y de su reflejo en la superación de su disparatada Sentencia Weiss, de 5 de mayo de 2020. $R E D C, 122,333-366$.

López Castillo, A., Saiz Arnaiz, A., y Ferreres Comella, V. (2005). Constitución Española y Constitución Europea. CEPC.

López Guerra, L. et alii (2018). Derecho Constitucional (11. a Ed., vol. I), Tirant lo Blanch.

Martín Rodríguez, P.J. (2020. Y sonaron las trompetas a las puertas de Jericó... en forma de sentencia del Bundesverfassungsgericht. And they blew the trumpets outside Jericho... with a judgment of the Bundesverfassungsgericht. Revista General de Derecho Europeo, 52. https://www.iustel.com//v2/revistas/detalle_revista. asp? $\mathrm{id}=13 \&$ numero $=52$

Miasik, D., y Szwarc, M. (2021). Primacy and direct effect-still together: Poplawski II. Common Market Law Review, 58, 2, 571-590.

Paris, D. (2018). Limiting the 'counter-limits'. National Constitutional Courts and the scope of the primacy of EU Law. En P. Faraguna, Ch. Fasone y g. Piccirilli (Eds.), Constitutional adjudication in Europe between unity and pluralism. The Italian Journal of Public Law,[][] 10, 2, 205-225.

Pech, L., y Kochenov, D. (2021). Respect for the Rule of Law in the Case Law of the European Court of Justice: A Casebook Overview of Key Judgments since the Portuguese Judges Case. SIEPS Report. 
Requejo, J. L. (2021). La ley desamparada. Consideraciones sobre el juez natural en la ley democrática de los Estados de la Unión Europea. En Asociación de Letrados del Tribunal Constitucional, Tribunal Constitucional y Tribunal de Justicia de la Unión Europea, TC-CEPC.

Rodríguez Iglesias, G.C. (2005). No existe contradicción entre la Constitución española y la Constitución europea: la Declaración del Tribunal Constitucional. Revista de Derecho Comunitario Europeo, 20, 5-16.

Rodríguez-Izquierdo Serrano, M. (2018). Los derechos fundamentales en el procedimiento por incumplimiento y la adecuación constitucional de las actuaciones de los Estados miembros. Revista de Derecho Comunitario Europeo, 61, 933-971.

Rodríguez-Izquierdo Serrano, M. (2021). Unión Europea y quiebras del Estado de Derecho: el recurso por incumplimiento como garantía impropia, En J.I. Ugartemendia Eceizabarrena y A. Saiz Arnaiz (Eds.), ¿Está en peligro el Estado de Derecho en la Unión Europea? (pp. 213-235). IVAP.

Rossi, L.S. (2017). The Principle of Equality Among Member States of the European Union. En L.S. Rossi y F. Casolari (Eds.), The Principle of Equality in EU Law (pp. 3-41), Springer.

Sadurski, W. (2021, 11 agos.). The Disciplinary Chamber May Go-but the Rotten System will Stay. VerfBlog. https://verfassungsblog.de/the-disciplinary-chamber-may-gobut-the-rotten-system-will-stay/

Sarmiento, D. (2020). El Derecho de la Unión Europea (3. ${ }^{a}$ Ed.). Marcial Pons.

Sarmiento, D. (2021). El Tribunal Constitucional Español y el diálogo judicial europeo. REDE, 77, 9-34.

Sarrión Esteve, J. (2020). Los límites a la integración europea en la doctrina constitucional. Comares.

Selejan-Gutan, B. (2021, 18 jun.). A Tale of Primacy Part. II: The Romanian Constitutional Court on a Slippery Slope. VerfBlog. https://verfassungsblog.dela-tale-of-primacypart-iil

Steinbeis, M. (2021, 9 oct.) “The exit door”, Verfassungsblog https://verfassungsblog.de/ the-exit-doorl

Steinbeis, M. (2021, 15 oct.) “After de explosión”, Verfassungsblog https://verfassungsblog.delafter-the-explosion/

Tănăsescu, E.-S., y Selejan-Gutan, B. (2021, 2 jun.). A Tale of Primacy: The ECJ Ruling on Judicial Independence in Romania. VerfBlog. https://verfassungsblog.de/a-tale-ofprimacy/

Turmo, A. (2021, 29 abr.). The French Data Network Judgment: A 'Securitarian Frexit' or Classic Conseil d'État Euroscepticism?. EU Law Live.

Ugartemendia Eceizabarrena, J.I. (2016). El control de comunitariedad de las resoluciones jurisdiccionales y el límite de la identidad constitucional, $R E D E, 59,13-43$.

Ugartemendia Eceizabarrena, J.I. (2021). The fundamental right to an effective judicial protection and the rule of law in the EU and their impact on Member States' administration of justice. Freedom, Security \& Justice. European Legal Studies, 1, 238-264.

Ugartemendia Eceizabarrena, J.I., y Donaire Villa, F.J. (2019). La triple justiciabilidad de las reformas constitucionales. Garantías jurisdiccionales nacionales, supranacionales e internacionales. Aranzadi-Thomson Reuters.

Vallée, S., y Genevoix, G. (2021, 25 abr.). A Securitarian Solange: France has launched a cluster bomb on the EU's legal and political order. VerfBlog. https://verfassungsblog.dela-securitarian-solangel

Von Bogdandy, A. y Paris, D. (2020). La forza si manifesta pienamente nella debolezza. Una comparazione tra la Corte costituzionale e il Bundesverfassungsgericht. Quaderni costituzionali, 1, 9-30. 
Weiler, J.H.H., y Sarmiento, D. (2020, 1 jun.). The EU Judiciary After Weiss-Proposing a New Mixed Chamber of the Court of Justice. EU Law Live.

Weiler, J.H.H., y Sarmiento, D. (2020, 6 jul.). The EU Judiciary After Weiss-Proposing A New Mixed Chamber of the Court of Justice. A Reply to Our Critics. EU Law Live.

Ziller, J. (2021, 24 abr.). The Conseil d'Etat refuses to follow the Pied Piper of Karlsruhe. VerfBlog. https://verfassungsblog.de/the-conseil-detat-refuses-to-follow-the-piedpiper-of-karlsruhe/

\section{B. Legislación y jurisprudencia}

Directiva 76/207/CEE del Consejo, de 9 de febrero de 1976, relativa a la aplicación del principio de igualdad de trato entre hombres y mujeres en lo que se refiere al acceso al empleo, a la formación y a la promoción profesionales, y a las condiciones de trabajo (DO L 039, 14 feb. 1976).

Directiva 93/37/CEE del Consejo, de 14 de junio de 1993, sobre coordinación de los procedimientos de adjudicación de los contratos públicos de obras (DO L 199/54, 9 ago. 1993).

Decisión Marco del Consejo, de 13 de junio de 2002, relativa a la orden de detención europea y a los procedimientos de entrega entre Estados miembros. DO L 190 (18 jul. 2002).

Comunicación de la Comisión al Parlamento Europeo y el Consejo, acerca del Informe sobre la situación del estado de derecho en la Unión Europea de 2021, https:// ec.europa.eu/info/files/communication-2021-rule-law-report-rule-law-situation-european-union

SentenciaTJUE.(1970).Internationale Handelsgesellschaft,C-11/70.ECLI:EU:C:1970:114.

Sentencia TJUE. (1978). Comisión c. Italia, C-100/77. ECLI:EU:C:1978:78.

Sentencia TJUE. (1980). Comisión c. Bélgica, C-102/79. ECLI:EU:C:1980:120.

Sentencia TJUE. (1984). Von Colson y Kamann, de 10 de abril de 1984, 14/83. ECLI:EU:C:1984:153.

Sentencia TJUE. (1987). Foto-Frost, C-314/85. ECLI:EU:C:1987:452.

Sentencia TJUE. (1990). Marleasing, C-106/89. ECLI:EU:C:1990:395.

Sentencia TJUE. (1991). Grogan, C-159/90. ECLI:EU:C:1991:378.

Sentencia TJUE. (1997). Inter-Environnement Wallonie, C-129/96. ECLI:EU:C:1997:628.

Sentencia TJUE. (1999). Carbonari y otros, C-131/97. ECLI:EU:C:1999:98.

Sentencia TJUE. (2000). Kreil, C-285/98. ECLI:EU:C:2000:2.

Sentencia TJUE. (2004). Pfeiffer y otros, C-397 a 401/01. ECLI:EU:C:2004:584.

Sentencia TJUE. (2006). A. Cordero Alonso, C-81/05. ECLI:EU:C:2006:529.

Sentencia TJUE. (2007). Comisión c. Alemania, C-503/04. ECLI:EU:C:2007:432.

Sentencia TJUE. (2008). Michaniki AE, C-213/07. ECLI:EU:C:2008:731.

Sentencia TJUE. (2010). Winner Wetten, C409/06. EU:C:2010:503.

Sentencia TJUE. (2010). Sorge, C-98/09. ECLI:EU:C:2010:369.

Sentencia TJUE. (2011). Landtová, C-399/09. ECLI:EU:C:2011:415.

Sentencia TJUE. (2013). Melloni, C-399/11. ECLI:EU:C:2013:107.

Sentencia TJUE. (2013). Križan y otros, C416/10. EU:C:2013:8.

Sentencia TJUE. (2014). Comisión c. Hungría, C-288/12. ECLI:EU:C:2014:237.

Sentencia TJUE. (2015). Taricco, C-105/14. ECLI:EU:C:2015:555.

Sentencia TJUE. (2016). Dansk Industri, C441/14. ECLI:EU:C:2016:278.

Sentencia TJUE. (2017). M.A.S. y M.B (Taricco II), C-42/17. ECLI:EU:C:2017:936.

Sentencia TJUE. (2018), Minister for Justice and Equality, C378/17. EU:C:2018:979.

Sentencia TJUE. (2018). Egenberger, C-414/16. ECLI:EU:C:2018:257.

Sentencia TJUE. (2018). Weiss, C493/17. ECLI:EU:C:2018:1000.

Sentencia TJUE. (2018). IR / JQ, C-68/17. ECLI:EU:C:2018:696. 
Sentencia TJUE. (2018). Minister for Justice and Equality y Commissioner of An Garda Síochána, C378/17. ECLI:EU:C:2018:979.

Sentencia TJUE. (2019), Pelham y otros, C476/17. EU:C:2019:624.

Sentencia TJUE. (2019). Poplawski II, C-573/17. ECLI:EU:C:2019:530.

Sentencia TJUE. (2019). A. K. yotros, C585/18, C624/18 y C625/18, ECLI:EU:C:2019:982.

Sentencia TJUE. (2020). La Quadrature du Net y otros, C-511/18, C- 512/18 y C- 520/18. ECLI:EU:C:2020:791.

Sentencia TJUE. (2021). Consob, C-481/19. ECLI:EU:C:2021:84.

Sentencia TJUE. (2021). A.B. y otros, C-824/18. ECLI:EU:C:2021:153.

Sentencia TJUE. (2021). Repubblika/II-Prim Ministru, C-896/19. ECLI:EU:C:2021:311.

Sentencia TJUE. (2021). Asociația 'Forumul Judecătorilor din România', asuntos acumulados C-83/19, C-127/19, C-195/19, C-291/19, C-355/19 y C-397/19. ECLI:UE:C:2021: 393.

Sentencia TJUE. (2021). Latvijas Republikas Saeima, C-439/19. ECLI:EU:C:2021:504.

Sentencia TJUE. (2021). Comisión c. Polonia, C-791/19. ECLI: UE: C:2021:596.

Sentencia TJUE. (2021). W.Ż., C-487/19, ECLI:EU:C:2021:798.

Auto TJUE. (2020). Comisión c. Polonia, C -791/19 R. ECLI:EU: C: 2020: 277.

Auto TJUE. (2021). Comisión c. Polonia, C-204/21 R. ECLI:EU:C:2021:593.

Auto TJUE. (2021) Comisión c. Polonia, C-204/21 R-RAP. ECLI:EU:C:2021:834.

Comunicado de prensa TJUE (2020, 8 may.)

Conclusiones AG Hogan (2020). Repubblika/II-Prim Ministru, C-896/19. ECLI:EU:C:2020:1055.

Conclusiones AG Tanchev (2020). A.B. y otros, C-824/18. ECLI:EU:C:2020:1053.

Sentencia TEDH. (2021). Xero Flor c. Polonia, n'. 4907/18

Sentencia TEDH. (2021). Reczkowicz c. Polonia, no 43447/19.

Declaración TC 1/1992 (1 jul.). ECLI:ES:TC:1992:1D.

Declaración TC 1/2004 (13 dic.). ECLI:ES:TC:2004:1D.

Sentencia TC 26/2014 (13 feb.). ECLI:ES:TC:2014:26.

Auto TC 86/2011 (9 jun.). ECLI:ES:TC:2011:86. .

Sentencia TC Alemán BVerfG (2010, 6 jul.). Honeywell, 2 BvR 2661/06.

Sentencia TC Alemán BVerfG-Sala 2. ${ }^{a}$ (2015, 15 dic.). 2 BvR 2735/14. ECLI:DE:BVerfG: 2015:rs20151215.2bvr273514.

Sentencia TC Alemán BVerfG-Sala 2. ${ }^{\text {a }}$ (2020, 5 may.). 2 BvR 859/15. ECLI:DE:BVerfG: 2020:rs20200505.2bvr08915.

Auto Corte Constitucional Italiana n ${ }^{\circ} .24$ (2017, 26 ene.). ECLI:IT:COST:2017:24.

Sentencia TC Portugal (2020, 15 jul.), nº. 422/2020.

Decisión TS Chipre (2005, 7 nov.). AP. n. ${ }^{\circ} 294 / 2005$.

Auto TS Polonia-Sala Disciplinaria (2020, 23 sep.). II DO 52/20.

Sentencia TC Polonia (2005, 27 abr.). P 1/05.

Sentencia TC Polonia (2021, 14 jul.). P 7/20.

Sentencia TC Polonia (2021, 7 oct.). K 3/21.

Decisión TC Rumanía (2021, 8 jun.). 390/2021. 